\title{
How aggregate volatility-of-volatility affects stock returns
}

Article

Accepted Version

Hollstein, F. and Prokopczuk, M. (2018) How aggregate volatility-of-volatility affects stock returns. The Review of Asset Pricing Studies, 8 (2). pp. 253-292. ISSN 2045-9939 doi: https://doi.org/10.1093/rapstu/rax019 Available at https://centaur.reading.ac.uk/75564/

It is advisable to refer to the publisher's version if you intend to cite from the work. See Guidance on citing.

To link to this article DOI: http://dx.doi.org/10.1093/rapstu/rax019

Publisher: Society for Financial Studies

All outputs in CentAUR are protected by Intellectual Property Rights law, including copyright law. Copyright and IPR is retained by the creators or other copyright holders. Terms and conditions for use of this material are defined in the End User Agreement.

\section{www.reading.ac.uk/centaur}

\section{CentAUR}

Central Archive at the University of Reading

Reading's research outputs online 


\title{
How Aggregate Volatility-of-Volatility Affects Stock Returns*
}

\author{
Fabian Hollstein ${ }^{\dagger}$ and Marcel Prokopczuk ${ }^{\dagger, \ddagger}$
}

January 18, 2017

\begin{abstract}
A stylized theoretical model with stochastic volatility suggests the existence of a trade-off between returns and volatility-of-volatility. Using the VVIX index as empirical measure, we confirm this prediction and detect that time-varying aggregate volatility-of-volatility commands an economically substantial and statistically significant negative risk premium. We find a two-standard deviation increase in aggregate volatility-of-volatility factor loadings to be associated with a decrease in average annual returns of about $11 \%$. This phenomenon cannot be explained by aggregate volatility, jump risk, and several other characteristics and factor sensitivities, or by a crisis effect.
\end{abstract}

\section{JEL classification: G12, G11}

Keywords: Aggregate economic uncertainty, stock market volatility-of-volatility, VVIX

*We are grateful to Zeno Adams, Jan Antell (discussant), I-Hsuan Ethan Chiang (discussant), David Feldman (discussant), Roland Füss, Anastasios Kagkadis, Paola Pederzoli (discussant), Michael Weber, and Chardin Wese Simen, as well as seminar participants at the meetings of the Eastern Finance Association, FMA Europe, Midwest Finance Association, Swiss Society for Financial Market Research and several seminars for valuable comments. We thank Chen Xue for kindly sharing his data. Contact: hollstein@fmt.unihannover.de (F. Hollstein) and prokopczuk@fmt.uni-hannover.de (M. Prokopczuk).

${ }^{\dagger}$ School of Economics and Management, Leibniz University Hannover, Koenigsworther Platz 1, 30167 Hannover, Germany.

${ }^{\ddagger}$ ICMA Centre, Henley Business School, University of Reading, Reading, RG6 6BA, UK. 


\section{Introduction}

In this paper, we study whether aggregate volatility-of-volatility influences stock returns. ${ }^{1}$ Aggregate volatility-of-volatility is important because it characterizes the distribution of stochastic volatility. While there seems to be a consensus that stochastic volatility is important for asset pricing (e.g., Ang et al., 2006b; Barndorff-Nielsen \& Veraart, 2012), volatilityof-volatility, thus far, has received considerably less attention. However, the volatility of stochastic volatility likely also carries important information on the current and future investment opportunity set. Hence, if an innovation to aggregate volatility-of-volatility predicts a worsening of future investment opportunities, investors seek to insure against this, demanding stocks with low sensitivities to innovations in volatility-of-volatility.

Using a simple stylized theoretical model with recursive preferences and consumption uncertainty in the spirit of Bollerslev et al. (2009) we motivate the existence of a volatilityof-volatility-return trade-off in addition to the commonly employed risk-return and volatilityreturn trade-offs. Based on the model predictions, we show empirically that volatility-ofvolatility is indeed significantly priced in the stock market.

We document the trade-off between volatility-of-volatility and returns using several steps. First, we show that market volatility-of-volatility, measured using the VVIX index, is distinct from market volatility. The shocks to the two measures are only moderately correlated (0.67) and the overall dynamics appear to be substantially distinct. Moreover, empirically, the VIX forecasts future market volatility, while the VVIX forecasts the future volatility of the VIX. Second, following the empirical framework of Ang et al. (2006a) and Cremers et al. (2015), we show that the single-sorted hedge portfolio on innovations in aggregate volatility-of-volatility yields an annual return of $-4.91 \%$ and an alpha of $-6.35 \%$ with respect to the factor model of Hou et al. (2015b). ${ }^{2}$ Additionally, using Fama \& MacBeth (1973) cross-sectional regressions, we find that a two-standard deviation increase in aggregate volatility-of-volatility factor loadings is associated with a significant decrease in average annual returns of about $11 \%$. We show that these results hold both for value-weighted and equally weighted sorts and

\footnotetext{
${ }^{1}$ Aggregate volatility-of-volatility denotes the volatility of the volatility of the aggregate stock market.

${ }^{2}$ The alpha with respect to the classical Carhart (1997) 4 -factor model is $-4.91 \%$, which is also significantly different from zero.
} 
regressions and prevail after controlling for canonical characteristics and popular market risk factors, including, e.g., beta, aggregate volatility, size, liquidity, and jump risk.

Third, we show that our findings are robust to various additional tests. Performing multivariate sensitivity estimations to control for various aggregate factors, our conclusions are unchanged. Likewise, we find that our results are not driven by the 2008-2009 financial crisis. Lastly, we show that innovations in aggregate volatility-of-volatility can be hedged using options written on the volatility index.

Our work is related to recent studies on uncertain volatility. Epstein \& Ji (2013) formulate a multiple priors model with ambiguity about volatility. Our approach is similar in that we consider uncertainty about volatility. However, we use a direct smooth measure to capture this uncertainty. Huang \& Shaliastovich (2014) show that there is a volatilityof-volatility risk premium in the cross-section of delta-hedged S\&P 500 and VIX options. Unlike Huang \& Shaliastovich (2014) we study the pricing of aggregate volatility-of-volatility in the cross-section of equity returns. Studying the cross-section of stock returns allows us to control for several other cross-sectional risk factors, which is not easily possible when working with hedged options portfolios. Baltussen et al. (2015) show that the volatility-ofvolatility of individual stocks is significantly negatively priced in the cross-section of stock returns. As opposed to our study, Baltussen et al. (2015) primarily use a measure of idiosyncratic volatility-of-volatility and cannot detect a significant effect using past sensitivities from aggregate factor specifications with high-minus-low idiosyncratic volatility-of-volatility portfolios or the volatility-of-volatility from at-the-money (ATM) S\&P 500 options. We, in turn, examine model-free aggregate market volatility-of-volatility, represented by the VVIX, as a state variable concentrating on systematic instead of idiosyncratic effects. Chen et al. (2014) measure volatility-of-volatility using high-frequency index option data and empirically find volatility-of-volatility to carry a significantly negative risk premium. Our study differs from theirs in two important dimensions. First, we directly use the VVIX index provided by the CBOE, instead of a high frequency intraday realized variance measure of the VIX index. Consequently, we use a forward-looking volatility measure instead of past variation in forward-looking volatility. This is important since there appears to be a consensus in the literature, that using implied instead of historical volatility estimates significantly improves 
prediction accuracy (e.g., Jiang \& Tian, 2005; Prokopczuk \& Wese Simen, 2014). Second, we present a model framework with recursive Epstein-Zin preferences and consumption uncertainty that rationalizes our empirical results.

Our work also connects to the literature on aggregate risk factors including Ang et al. (2006b), Adrian \& Rosenberg (2008), Han \& Zhou (2012), Chang et al. (2013), Lettau et al. (2014), and Cremers et al. (2015). However, our focus is different. While previous studies test whether aggregate volatility, its components, or higher moments are priced, we complement the existing literature by examining the implications of aggregate volatility-of-volatility for the stock market.

Finally, our paper relates to the literature on long-run risks pioneered by Bansal \& Yaron (2004). Our empirical model especially builds on Bollerslev et al. (2009), Campbell et al. (2014) and Bali \& Zhou (2015). We show that with the model assumptions commonly employed in the literature, especially those of more recent works, the expected return beta representation implies that volatility-of-volatility is priced in asset markets.

The remainder of this paper is organized as follows. Section II presents a simple model that implies a trade-off of aggregate volatility-of-volatility and stock returns. Section III describes our dataset and methodology. Section IV presents our empirical results with portfolio sorts and cross-sectional regressions. Section V presents further analyses and robustness tests. Finally, Section VI concludes. Appendices A and B provide detailed descriptions of all variables used in the paper.

\section{Model Formulation}

We build on the results of Bollerslev et al. (2009), Campbell et al. (2014), and Bali \& Zhou (2015) and impose a stylized intertemporal asset pricing model with stochastic volatility to theoretically motivate the volatility-of-volatility-return trade-off.

The representative agent has Epstein \& Zin (1989) preferences with the value function $V_{g, t}$ as

$$
V_{g, t}=\left[(1-\delta) C_{t}^{\frac{1-\gamma}{\theta}}+\delta\left(E_{t}\left[V_{g, t+1}^{1-\gamma}\right]\right)^{\frac{1}{\theta}}\right]^{\frac{\theta}{1-\gamma}}
$$


where $C_{t}$ is the consumption at time $t$, and the preference factors of the representative agent are denoted by $\delta$, the subjective discount factor, and $\gamma$, the coefficient of relative riskaversion. As is commonly done, for convenience we define $\theta=(1-\gamma) /(1-1 / \psi)$, with $\psi$ being the elasticity of intertemporal substitution. As shown by Epstein \& Zin (1991), the corresponding stochastic discount factor (SDF) can be expressed as

$$
M_{t+1}=\left(\delta\left(\frac{C_{t}}{C_{t+1}}\right)^{1 / \psi}\right)^{\theta}\left(\frac{W_{t}-C_{t}}{W_{t+1}}\right)^{1-\theta}
$$

$W_{t}$ is the market value of the agent's consumption stream. The logarithm of the SDF is then

$$
m_{t+1}=\theta \ln \delta-\frac{\theta}{\psi} g_{t+1}+(\theta-1) r_{t+1}
$$

$r_{t+1}=\ln \left(W_{t+1} /\left(W_{t}-C_{t}\right)\right)$ is the $\log$ return on wealth and $g_{t+1}=\Delta c_{t+1}$ is the log consumption growth. We follow Bollerslev et al. (2009) and Bali \& Zhou (2015) assuming the following joint dynamics for consumption growth and consumption growth volatility

$$
\begin{aligned}
g_{t+1} & =\mu_{g}+\sqrt{\sigma_{g, t}^{2}} z_{t+1}, \\
\sigma_{g, t+1}^{2} & =a_{\sigma}+\rho_{\sigma} \sigma_{g, t}^{2}+\sqrt{q_{t}} z_{v, t+1} \\
q_{t+1} & =a_{q}+\rho_{q} q_{t}+\varphi_{q} \sqrt{q_{t}} z_{q, t+1} .
\end{aligned}
$$

$\mu_{g}$ is the constant mean growth rate, $\sigma_{g, t}^{2}$ denotes the conditional variance of consumption growth, $q_{t}$ represents the volatility uncertainty process, while $z_{t+1}, z_{v, t+1}$, and $z_{q, t+1}$ describe independent i.i.d. $N(0,1)$ processes. The parameters satisfy $a_{\sigma}>0, a_{q}>0,\left|\rho_{\sigma}\right|<1$, $\left|\rho_{q}\right|<1$, and $\varphi_{q}>0$.

Let $\omega_{t}$ denote the logarithm of the price-dividend ratio, or price-consumption or wealthconsumption ratio, of the asset that pays the consumption endowment. To find the equilibrium, one can conjecture a solution for $\omega_{t}$ as an affine function of the state variables $\sigma_{g, t}^{2}$ and $q_{t}$

$$
\omega_{t}=A_{0}+A_{\sigma} \sigma_{g, t}^{2}+A_{q} q_{t}
$$

Using the standard Campbell \& Shiller (1988) approximation $r_{t+1}=\kappa_{0}+\kappa_{1} \omega_{t+1}-\omega_{t}+g_{t+1}$, 
a solution for the coefficients $A_{0}, A_{\sigma}$, and $A_{q}$ can be obtained (Bollerslev et al., 2009). Note that, assuming $\gamma>1$ and $\psi>1$, hence $\theta<0$, it holds that both $A_{\sigma}<0$ and $A_{q}<0$. Substituting the Campbell \& Shiller (1988) approximation into Equation (3), one obtains a pricing kernel without reference to consumption growth (Campbell et al., 2014; Bali \& Zhou, 2015)

$$
m_{t+1}=\theta \ln \delta+\frac{\theta}{\psi} \kappa_{0}-\frac{\theta}{\psi} \omega_{t}+\frac{\theta}{\psi} \kappa_{1} \omega_{t+1}-\gamma r_{t+1}
$$

Assuming a conditional joint log-normal distribution with time-varying volatility for the asset returns, the risk premium on any asset $j$ is given by

$$
E_{t}\left(r_{j, t+1}\right)-r_{f, t}+\frac{1}{2} \operatorname{Var}_{t}\left(r_{j, t+1}\right)=-\operatorname{Cov}_{t}\left(m_{t+1}, r_{j, t+1}\right)
$$

Inserting the pricing kernel without reference to consumption growth in Equation (8) into Equation (9), one can obtain an ICAPM pricing relation of the following form:

$$
E_{t}\left(r_{j, t+1}\right)-r_{f, t}+\frac{1}{2} \operatorname{Var}_{t}\left(r_{j, t+1}\right)=\gamma \operatorname{Cov}_{t}\left(r_{t+1}, r_{j, t+1}\right)-\frac{\theta}{\psi} \kappa_{1} \operatorname{Cov}_{t}\left(\omega_{t+1}, r_{j, t+1}\right)
$$

Inserting Equation (7) into Equation (10) yields:

$$
\begin{aligned}
& E_{t}\left(r_{j, t+1}\right)-r_{f, t}+\frac{1}{2} \operatorname{Var}_{t}\left(r_{j, t+1}\right) \\
& \quad=\gamma \operatorname{Cov}_{t}\left(r_{t+1}, r_{j, t+1}\right)-\frac{\theta}{\psi} \kappa_{1} A_{\sigma} \operatorname{Cov}_{t}\left(\sigma_{g, t+1}^{2}, r_{j, t+1}\right)-\frac{\theta}{\psi} \kappa_{1} A_{q} \operatorname{Cov}_{t}\left(q_{t+1}, r_{j, t+1}\right) .
\end{aligned}
$$

Apart from the variance term $\operatorname{Var}_{t}\left(r_{j, t+1}\right)$, there is the usual risk-return trade-off $\gamma$, a trade-off of returns and variance $-\frac{\theta}{\psi} \kappa_{1} A_{\sigma}$, and a volatility-of-volatility-return trade-off $-\frac{\theta}{\psi} \kappa_{1} A_{q}$ can be detected from this formulation. This formulation may already directly serve as a motivation for why both shocks to volatility and volatility-of-volatility should be priced in the stock market. However, in this formulation, $\sigma_{g, t+1}^{2}$ and $q_{t+1}$ represent the moments of the consumption processes.

The model also makes direct predictions on the relation of the expected return on wealth and the consumption moment. From this, one can directly infer information on the variance of the return on aggregate wealth (Bollerslev et al., 2009) as well as on volatility-of-volatility 
on aggregate wealth. We use the equations $\sigma_{r, t}^{2} \equiv \operatorname{Var}_{t}\left(r_{t+1}\right)=\sigma_{g, t}^{2}+\kappa_{1}^{2}\left(A_{\sigma}^{2}+A_{q}^{2} \varphi_{q}^{2}\right)$ and $Q_{t} \equiv \operatorname{Var}_{t}\left(\sigma_{r, t+1}^{2}\right)=q_{t}\left(1+\varphi_{q}^{2} \kappa_{1}^{4}\left(A_{\sigma}^{2}+A_{q}^{2} \varphi_{q}^{2}\right)^{2}\right)$, to obtain the following relation:

$$
\begin{aligned}
E_{t}\left(r_{j, t+1}\right)- & r_{f, t}+\frac{1}{2} \operatorname{Var}_{t}\left(r_{j, t+1}\right) \\
= & \gamma \operatorname{Cov}_{t}\left(r_{t+1}, r_{j, t+1}\right)-\frac{\theta}{\psi} \kappa_{1} A_{\sigma} \operatorname{Cov}_{t}\left(\sigma_{r, t+1}^{2}, r_{j, t+1}\right) \\
& +\frac{\theta}{\psi} \frac{\kappa_{1}\left[A_{\sigma} \kappa_{1}^{2}\left(A_{\sigma}^{2}+A_{q}^{2} \varphi_{q}^{2}\right)-A_{q}\right]}{\left[1+\varphi_{q}^{2} \kappa_{1}^{4}\left(A_{\sigma}^{2}+A_{q}^{2} \varphi_{q}^{2}\right)\right]} \operatorname{Cov}_{t}\left(Q_{t+1}, r_{j, t+1}\right) .
\end{aligned}
$$

Equation (12) directly predicts a relation of current excess returns with variance and volatility-of-volatility of aggregate wealth. Note, however, that technically, $\operatorname{Cov}_{t}\left(\sigma_{r, t+1}^{2}, r_{j, t+1}\right)$ and $\operatorname{Cov}_{t}\left(Q_{t+1}, r_{j, t+1}\right)$ denote the time- $t$ covariances of asset returns with $t+1$ expectations of variance and volatility-of-volatility over time $t+2$. Hence, for these higher-order terms to be estimable and the model to be directly applicable, we have to assume that the current expectation of aggregate variance and aggregate volatility-of-volatility provide good proxies for next-period expectations. ${ }^{3}$ Further, note that Equation (12) implies a relation of the variance as well as, technically, the variance-of-variance of total wealth with stock returns. In our empirical tests, we use shocks to the empirically more robust measures of aggregate volatility and aggregate volatility-of-volatility (e.g., Merton, 1980). However, shocks to both volatility and squared volatility always have the same sign and are highly correlated by construction. Hence, for the purpose of motivating our empirical analysis, although not perfectly similar, the model delivers a reasonable description.

Transforming Equation (12) to a conditional beta representation, replacing the conditional covariances with conditional betas, we get

$$
E_{t}\left(r_{j, t+1}\right)-r_{f, t}+\frac{1}{2} \operatorname{Var}_{t}\left(r_{j, t+1}\right)=\tilde{Y} \cdot \beta_{j, t}^{\mathrm{M}}+\tilde{V} \cdot \beta_{j, t}^{\mathrm{V}}+\tilde{Z} \cdot \beta_{j, t}^{\mathrm{Q}}
$$

$\tilde{Y}, \tilde{V}$, and $\tilde{Z}$ denote the risk premia, while $\beta_{j, t}^{\mathrm{M}}, \beta_{j, t}^{\mathrm{V}}$, and $\beta_{j, t}^{\mathrm{Q}}$ are the conditional market, variance, and volatility-of-volatility betas.

From Equation (12), one can infer the model predictions on the market prices of risk.

\footnotetext{
${ }^{3}$ In our empirical study, we use daily observations. Our proxies for aggregate volatility and volatilityof-volatility denote expectations over the next 30 days. Hence, due to the large overlap of our empirical measures, this assumption appears reasonable.
} 
The market prices of risk are proportional to the derivative of the negative of the stochastic discount factor to shocks in the state variables. It can be easily shown that the market price of risk of shocks to aggregate wealth is positive, and, given that the parameters satisfy $\psi>1$, $\theta<0$, and $A_{\sigma}<0$ as well as $A_{q}<0$, the market price of shocks to variance is negative. The market price of risk on aggregate volatility-of-volatility is not clearly signed and depends on the relation of $A_{\sigma} \kappa_{1}^{2}\left(A_{\sigma}^{2}+A_{q}^{2} \varphi_{q}^{2}\right)$ and $A_{q}$.

\section{Data and Methodology}

\section{A Data}

We base our study on all stocks traded on the New York Stock Exchange (NYSE), the American Stock Exchange (AMEX), and the National Association of Securities Dealers Automated Quotations (NASDAQ) that are classified as ordinary common shares (Center for Research in Security Prices (CRSP) share codes 10 or 11), excluding closed-end funds and REITS (SIC codes 6720-6730 and 6798), for the sample period between March 01, 2006 and September 30, 2016. We obtain data on the VIX and the VVIX from the CBOE. The VIX is constructed so that it represents the model-free 30-day implied volatility of the S\&P 500 index. On February 24, 2006, the CBOE began trading options written on the VIX and recently the CBOE started reporting the VVIX, which represents the model-free 30-day implied volatility of the VIX. ${ }^{4,5}$ We also obtain five-minute intraday high-frequency data on the VIX and the S\&P 500 from the Thompson Reuters Tick History (TRTH) database.

We obtain daily and monthly price data as well as data on dividend payments, trading volumes, firm age, and shares outstanding from CRSP. Following Amihud (2002) and Zhang (2006), we exclude "penny stocks" with prices below 1 dollar. Additionally, we require a market capitalization of at least 225 million dollars (D'Avolio, 2002; Baltussen et al., 2015). These two thresholds serve to eliminate the most illiquid stocks that exhibit potential

\footnotetext{
${ }^{4}$ For the period prior to 2007, we compute the VVIX ourselves using the VIX methodology and options on the VIX from OptionMetrics.

${ }^{5}$ For reliable implied moments, option liquidity is an important issue. The average daily trading volume of VIX options was already greater than 8,000 in February 2006. It increased gradually to more than 500,000 contracts per day towards the end of the sample. For more information, refer to the CBOE homepage.
} 
microstructure problems and may bias the results (Fama \& French, 2008). Furthermore they ensure that only stocks with relatively low short-sale constraints are selected (D'Avolio, 2002). On average, these selection criteria result in about 2,396 stocks included in our sample per month. ${ }^{6}$ We adjust for delisting returns following Shumway (1997) and Shumway \& Warther (1999).

We collect balance sheet and income statement data from the Compustat database. Options data are from the IvyDB OptionMetrics database. ${ }^{7}$ Data on the Fama \& French (1993) and momentum factors as well as the risk-free (Treasury Bill) rate are from Kenneth French's data library. We obtain data on the Pastor \& Stambaugh (2003) liquidity factor from Robert Stambaugh's homepage and data on the Hou et al. (2015b) factors directly from Chen Xue. ${ }^{8}$

We provide detailed variable definitions of all variables used in the paper in Appendices $\mathrm{A}$ and $\mathrm{B}$.

\section{B Empirical Framework}

Our goal is to test whether stocks with different sensitivities to innovations in aggregate volatility-of-volatility have different returns. To examine that, we follow a large body in the asset pricing literature, and examine the contemporaneous relation between realized factor loadings and realized returns (e.g., Black et al., 1972; and Fama \& French, 1992; among many others). Ang et al. (2006a) argue that while pre-formation factor loadings reflect both actual variation in factor loadings and measurement error, post-formation factor loadings are almost exclusively affected by stock return covariations with risk factors. Additionally, they point out that if risk exposures, and hence factor loadings, are highly time-varying, pre-formation factor loadings might be poor predictors of ex post risk exposures, leaving the analysis with low power to detect relations between factor loadings and realized returns. Addressing these concerns, our research design follows Ang et al. (2006a) and Cremers et al.

\footnotetext{
${ }^{6}$ The minimum is at 1,807 stocks eligible in February 2009, while the maximum results in April 2006, with 2,794 stocks. The total number of firm-month observations is 280,333 .

${ }^{7}$ Options data has only been available up to April 30, 2016 when we revised this manuscript. Hence, all tests that include options data (e.g., jump, dSkew) are performed for the sample period until April 30, 2016.

${ }^{8}$ The data from Chen Xue is monthly and only ranges until December 2015. Therefore, we construct the factors ourselves following the description in Hou et al. (2015a) to add the data for January until September 2016 as well as to obtain daily returns on the factors.
} 
(2015) by estimating factor loadings for individual stocks using daily returns over rolling annual periods from the regression:

$$
r_{j, \tau}-r_{f, \tau}=\alpha_{j, t}+\beta_{j, t}^{\mathrm{M}}\left(r_{M, \tau}-r_{f, \tau}\right)+\beta_{j, t}^{\mathrm{V}} d V I X_{\tau}+\beta_{j, t}^{\mathrm{Q}} d V V I X_{\tau}+\epsilon_{j, \tau}
$$

$r_{j, \tau}$ is the daily return of asset $j$ on day $\tau, r_{M, \tau}$ is the return of the market on that day, and $r_{f, \tau}$ is the risk-free rate. $d V I X_{\tau}$ and $d V V I X_{\tau}$ are the daily innovation in the VIX (Ang et al., 2006b) and VVIX indices.

To mirror the specification implied by our theoretical model in Equation (13), the regression in Equation (14) only includes the market excess return, innovations in aggregate volatility, and innovations in aggregate volatility-of-volatility. Furthermore, Ang et al. (2006b) argue that including additional factors in the regression in Equation (14) may add a lot of noise. We control for further factors when performing the time series and cross-sectional asset pricing tests. As a robustness check and to account for possible model mis-specification, we also consider multivariate joint factor loading estimations controlling for several aggregate risk factors previously documented in the literature:

$$
r_{j, \tau}-r_{f, \tau}=\alpha_{j, t}+\beta_{j, t}^{\mathrm{M}}\left(r_{M, \tau}-r_{f, \tau}\right)+\beta_{j, t}^{\mathrm{V}} d V I X_{\tau}+\beta_{j, t}^{\mathrm{Q}} d V V I X_{\tau}+\beta_{j, t}^{\zeta} \zeta_{\tau}+\epsilon_{j, \tau}
$$

$\zeta_{\tau}$ contains one or more market factors, such as the Fama \& French (1993) and Hou et al. (2015b) factors, the innovations in market skewness and kurtosis (dSkew, dKurt) as shown by Chang et al. (2013), the Cremers et al. (2015) straddle vol and jump factors, or innovations in the market variance risk premium (Han \& Zhou, 2012; dVRP). For the regressions in Equations (14) and (15), we use daily returns over rolling annual periods to estimate the sensitivities. For each period and stock, we require at least one hundred non-missing return observations in order to estimate the factor sensitivities. ${ }^{9}$

Turning the focus on the measurement of innovations in an economic variable, there

\footnotetext{
${ }^{9}$ For the factor loading estimation regressions, potentially low explanatory power might be a concern. In the basic specification, we find the model in Equation (14) to exhibit an average R-squared of 0.31 with median 0.29. Thus, it can be concluded that the factor loading regressions possess substantial explanatory power. In these regressions, the coefficient $\beta_{j, t}^{\mathrm{M}}$ is significantly different from zero (at 10\%) in $96 \%$ of the cases while the coefficients $\beta_{j, t}^{\mathrm{V}}$ and $\beta_{j, t}^{\mathrm{Q}}$ are significantly different from zero in about $19 \%$ and $13 \%$ of the cases, respectively.
} 
generally exists a trade-off between a possible errors-in-variables problem using simple first differences, if that fails to completely filter out the expected movement, versus the danger of misspecifying a more complex equation for the expected movement in a variable (Chen et al., 1986). We choose to measure the innovations in the VVIX index using the daily first differences in the variable, similar to the way Ang et al. (2006b) obtain innovations in the VIX, because the VVIX is highly serially correlated with a first-order autocorrelation of 0.94 during our sample period. Therefore, the current value of VVIX appears to be a relatively good proxy for tomorrow's expectation making the first difference quite adequately capture its innovation. For robustness, we also consider measuring innovations in aggregate volatilityof-volatility by fitting an ARMA $(1,1)$ model on the complete time series of the VVIX index. This approach results in a measure of innovations of $d V V I X_{\tau}=V V I X_{\tau}-0.9989 V V I X_{\tau-1}+$ $0.0839 d V V I X_{\tau-1}$. The results of both approaches are qualitatively similar, which is further discussed in the next section. ${ }^{10}$

\section{Empirical Results}

\section{A Descriptive Statistics}

In addition to various firm characteristics, we consider the impact of several aggregate state variables that have previously been examined in the literature. In Table 1 we report the sample correlations between daily innovations in aggregate volatility-of-volatility (dVVIX), innovations in aggregate volatility (dVIX; Ang et al., 2006b), the Fama \& French (1993), Carhart (1997), and Hou et al. (2015b) factors, and also the factors on market skewness and kurtosis of Chang et al. (2013), stochastic volatility and jump risk of Cremers et al. (2015), and innovations in the market variance risk premium (Han \& Zhou, 2012).

First, we note that whether innovations are measured as simple first differences (dVVIX)

\footnotetext{
${ }^{10}$ One may argue that the innovation in the VVIX captures both the innovation in aggregate volatilityof-volatility and in the volatility-of-volatility risk premium. However, trying to estimate the risk premium as the difference between the expected volatility-of-volatility, obtained using VIX futures and the VVIX as described for the market variance risk premium in Appendix A, and the risk-neutral expectation, we find the innovations in the risk premium to be only weakly related to total innovations in the VVIX with a correlation of -0.12 . Furthermore, when separating innovations in the VVIX from innovations in the risk premium and testing their significance in a joint cross-sectional regression, we find that only the "true" innovations in aggregate volatility-of-volatility are significantly priced. These results are available upon request.
} 


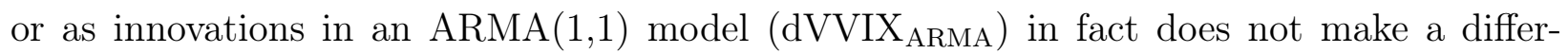
ence. The two innovation measures are perfectly correlated. There is a negative correlation of dVVIX with MKT of -0.55 . The linear relation between dVVIX and dVRP, jump, and dVIX, to which it might be related by construction, is of similar magnitude. ${ }^{11}$ Correlations of dVVIX with other factors are negligible. Consequently, aggregate volatility-of-volatility appears to be distinct from other factors documented in the previous literature. In Table A1 of the online appendix, we also examine the Spearman rank correlations of the aggregate factor sensitivities. In general, these are very low. The rank correlation of aggregate volatility-ofvolatility and volatility sensitivities is even negative with -0.40 and substantially smaller in magnitude than the correlation of factor innovations.

We provide further summary statistics in Table 2. In Panel A it can be seen that mean and median innovations in the VVIX are close to zero. Measuring innovations in the VVIX using the first difference is shown to result in a factor with very low autocorrelation $(-0.13)$, whereas using residuals from the fitted ARMA-model reduces the first-order autocorrelation to practically zero. The remaining factors are mostly constructed as returns with means close to zero and negligible autocorrelations.

Panels B and C of Table 2 present yearly summary statistics on the VVIX and $\beta_{j, t}^{\mathrm{Q}}$ factors of individual stocks, respectively. It is quite interesting to observe that the yearly average level of the VVIX is smallest in the crisis year 2009. In the years 2011, 2012, 2015, and 2016 the average volatility-of-volatility is substantially higher with values above 0.9 . In 2013 , there is a sharp decrease, almost returning to the 2009 level. The mean and median sensitivities of individual stocks to innovations in aggregate volatility-of-volatility, $\beta_{j, t}^{\mathrm{Q}}$, presented in Panel $\mathrm{C}$, are mostly close to zero. The highest average $\beta_{j, t}^{\mathrm{Q}}$ and average cross-sectional standard deviation results for rolling annual estimation periods starting in 2008.

The time series of the VIX and VVIX are plotted in Figure 1. We find that the level of the VVIX is higher than that of the VIX throughout the entire sample period. The averages of the VVIX and VIX are 0.87 and 0.20, respectively. Both, the S\&P 500 and the VIX

\footnotetext{
${ }^{11}$ Bollerslev et al. (2009) show that volatility-of-volatility is theoretically (positively) linked to the variance risk premium. However, the sign depends on the definition of the variance risk premium as risk-neutral minus physical expected variance. While we define it the other way around, our results are fully consistent with their derivation.
} 
are directly tradable, e.g., using futures on the respective indexes. Thus, the underlyings of the option-implied volatilities are comparable and our results indicate that the risk-neutral expectations of the variance of the returns on the VIX is substantially higher than that of the returns on the S\&P 500. Furthermore, the VVIX itself is by far more volatile and less persistent compared to the VIX. The VVIX exhibits pronounced spikes that correspond with news increasing economic uncertainty. For these news, typically the spikes in the VIX are by far less pronounced or not perceptible. These news events include, e.g., the Bear Sterns Hedge Funds Collapse (August 2007), the Lehman Brothers bankruptcy (September 2008), the Freddie Mac and Fannie Mae crisis (May 2010), and the near collapse of the Russian ruble (December 2014). Consequently, this stylized evidence provides further insights for the notion that VVIX is a proxy for economic uncertainty, distinct from volatility.

One may wonder whether the VVIX helps predict future volatility and volatility-ofvolatility. To analyze this, we estimate predictive regressions for the realized volatility of the S\&P 500 and the VIX. We use the end-of-month observations of the VIX and VVIX to predict the realized volatility, based on 5-minute returns, over the subsequent month. We present the results in Table 3. We find that, univariately, both the VIX and the VVIX significantly predict future realized variance. However, in a multivariate predictive regression, only the VIX significantly predicts the future realized volatility of the market index. On the other hand, we find that only the VVIX positively predicts the future realized volatility-ofvolatility, both in a univariate and a multivariate framework. These results are consistent with those in Huang \& Shaliastovich (2014) for a shorter sample period.

Overall, the results indicate that aggregate volatility-of-volatility, measured by the VVIX, and aggregate volatility, measured by the VIX, have differential dynamics and are only weakly related.

\section{B Portfolio Sorts and Characteristics}

To test whether aggregate volatility-of-volatility is priced in the stock market, we first

perform portfolio sorts. At the beginning of each month, we sort the stocks in ascending order with respect to their sensitivities to innovations in volatility-of-volatility $\left(\beta_{j, t}^{\mathrm{Q}}\right)$ over the following year. We form quintile portfolios, so that quintile 1 contains the stocks with 
the lowest exposure to aggregate volatility-of-volatility while quintile 5 contains those stocks with the highest volatility-of-volatility factor loadings. The hedge portfolio (5 minus 1 ) buys the quintile of stocks with the highest exposure and simultaneously sells the stocks in the quintile with the lowest exposure to aggregate volatility-of-volatility. The portfolio sorting approach maximizes the spread in the exposure to aggregate volatility-of-volatility and, thus, differences in average returns can be quite accurately attributed to differences in the sorting variable. Fama \& French (2008) point out that by building value-weighted portfolios the hedge portfolio can be dominated by few big stocks, whereas for equally weighted portfolios the hedge portfolio can be dominated by micro caps. To address this issue, we analyze both value-weighted and equally weighted portfolio sorts. For the portfolio sorts, within each quintile, we weight the stocks by their relative market value at the beginning of the estimation period for $\beta_{j, t}^{\mathrm{Q}}$. While our research design involves successive twelve-month periods employing partly overlapping information, it introduces moving average effects. To account for that, in all analyses, we adjust the standard errors following Newey \& West (1987) using twelve lags. ${ }^{12}$

Table 4 reports various summary statistics for the quintile portfolios sorted by contemporaneous volatility-of-volatility-sensitivities. We find that the average annual raw return obeys a nearly strictly monotonically decreasing pattern, from $10.0 \%$ and $10.6 \%$ in quintiles 1 and 2 to $5.1 \%$ in quintile 5 . Consequently, the better the stocks insure against positive shocks to aggregate volatility-of-volatility, the lower are their returns on average. The difference in raw returns of $-4.91 \%$ between quintiles 5 and 1 is statistically significant with a p-value of 2.7\%. Looking at the line labeled CAPM alpha, which reports the results when controlling for systematic risk, we find a similar abnormal return for the 5 minus 1 portfolio of $-4.87 \%$, which is also significant at 5\%. Controlling for the Carhart (1997) factors (4-factor) and additionally including the Pastor \& Stambaugh (2003) factor (5-factor) leads to alphas of $-4.91 \%$ and $-4.62 \%$ per year, both significant at $5 \%$. The alpha relative to the new factor model by Hou et al. (2015b) amounts to $-6.35 \%$, which is also significant at $5 \%{ }^{13}$ Conse-

\footnotetext{
${ }^{12}$ While theoretically only eleven lags are required, we follow Ang et al. (2006a) and Cremers et al. (2015) including an additional lag for robustness.

${ }^{13}$ In light of the results of Fabozzi et al. (2016), we decide to use the model of Hou et al. (2015b) instead of that of Fama \& French (2015). We thank the editor, Raman Uppal, for suggesting this.
} 
quently, accounting for systematic risk factors, the 5 minus 1 portfolio is expected to earn substantially higher returns than realized. This effect is mostly driven by the portfolio of the stocks with the highest sensitivities to innovations in aggregate volatility-of-volatility. For each factor model specification, the alpha of this portfolio is strongly significantly negative, while that of portfolio 1 is close to zero. Hence, investors are willing to pay a premium in order to hold stocks with high sensitivities to innovations in aggregate volatility-of-volatility while the stocks with the lowest sensitivities do not earn significant positive abnormal returns. We obtain similar results for value-weighted returns. The return and the alpha on the 5 minus 1 portfolio is typically even larger than for the equally weighted approach, although the significance of the abnormal returns of the hedge portfolio is typically slightly weaker.

In the remainder of Table 4, we examine value-weighted characteristics of the portfolios. The 5 minus 1 portfolio has a significantly positive exposure to the market excess return. The average market beta of the hedge portfolio of 0.31 would, following the logic of the CAPM, predict a substantially positive excess return, whereas the return that is realized is significantly negative. Interestingly, the hedge portfolio has a significantly negative exposure to aggregate volatility. The exposure to aggregate volatility-of-volatility is monotonically increasing by construction. Furthermore, we find that the firms in portfolio 5 on average are smaller than those in portfolio 1, have higher book-to-market ratios, are younger, and have slightly higher bid-ask spreads and leverage.

Another interesting issue relates to the time-series of excess returns of the 5 minus 1 hedge portfolio, presented in Figure 2. First, this analysis shows whether the cumulative returns are generated by a certain time period. Second, the plot also shows the periods where the insurance strategy pays off. To obtain a time-series of monthly returns, we average the returns of all active portfolios during that month. ${ }^{14}$ We present the results for both value- and equally weighted portfolios in Figure 2. Over the entire sample period, the cumulative excess return is roughly $-37 \%$ for the value-weighted and $-32 \%$ for the equally weighted portfolios. The trend is in general negative but there are also periods for which the insurance strategy pays off and the 5 minus 1 portfolio yields large positive returns. These times roughly

\footnotetext{
${ }^{14}$ Due to the overlapping approach with 12 -month holding periods, typically, there are 12 active 5 minus 1 hedge portfolios.
} 
correspond with the first half of 2008, where the National Bureau of Economic Research (NBER) indicates a recession, as well as short time periods in the beginning of 2009, in the beginning of 2012, in the second half of 2014, and in the beginning of 2016. These time periods typically correspond with positive innovations in and correspondingly high levels of the VVIX index.

\section{Double Sorts}

Given the close relation of aggregate volatility-of-volatiltiy and aggregate volatility and also the market variance risk premium (as shown by Bollerslev et al., 2009), we aim to further dissect the effects of these variables. To do that, we estimate the factor sensitivities in a joint regression and perform a double-sort. ${ }^{15}$

At the beginning of each month we independently sort all stocks into quintiles, using NYSE breakpoints, on the characteristic we want to control for as well as on their VVIXsensitivities (Novy-Marx, 2013). ${ }^{16}$ This results in a total of 25 portfolios. Thus, we obtain quintile portfolios on the exposure to aggregate volatility-of-volatility controlling for another characteristic without making assumptions on the parametric form of the relationships. For each quintile of both sorting variables, we obtain a 5 minus 1 hedge portfolio by buying the final portfolio 5 and selling portfolio 1 in the quintile. We consider both equally and value-weighted portfolios. For value-weighted portfolios, within each of the 25 portfolios we weight the stocks by their relative market value at the beginning of the estimation period for the exposures to aggregate volatility-of-volatility.

Table 5 reports all 25 portfolios resulting from the double sorts as well as the respective 5 minus 1 portfolios. We report Hou et al. (2015b) factor alphas and robust Newey \& West (1987) p-values in brackets. ${ }^{17}$ Panels A and B report the results for equally and valueweighted double sorts with respect to volatility-of-volatility and volatility betas. According

\footnotetext{
${ }^{15}$ For double sorts with aggregate volatility, we directly obtain the betas from Equation (14). When controlling for the variance risk premium, we use the same regression equation, replacing $d V I X_{\tau}$ by $d V R P_{\tau}$.

${ }^{16}$ While the double-sorting approach we use is unconditional, the results are qualitatively similar when performing a conditional double sort, i.e., first sorting on a certain characteristic and subsequently sorting on the VVIX-sensitivities. These results are available upon request.

${ }^{17}$ The results for Carhart (1997) 4-factor alphas are qualitatively similar. These results are available upon request.
} 
to the model's result in Equation (13), there are three risk factors in the market. Stock returns depend on the stocks' $\beta_{j, t}^{\mathrm{M}}, \beta_{j, t}^{\mathrm{V}}$, and $\beta_{j, t}^{\mathrm{Q}}$. Hence, given that the price of risk on both volatility and volatility-of-volatility appear to be negative, stocks with low $\beta_{j, t}^{\mathrm{V}}$ and low $\beta_{j, t}^{\mathrm{Q}}$ should earn high average returns. For each quintile of $\beta_{j, t}^{\mathrm{V}}$, stocks with higher $\beta_{j, t}^{\mathrm{Q}}$ should earn lower returns. Similarly, for each quintile of $\beta_{j, t}^{\mathrm{Q}}$, stocks with higher $\beta_{j, t}^{\mathrm{V}}$ should earn lower returns. This is exactly the pattern we find in Panels A and B of Table 5. Portfolios with both low $\beta_{j, t}^{\mathrm{V}}$ and low $\beta_{j, t}^{\mathrm{Q}}$ have positive alphas. Both, with increasing volatility-betas and volatility-of-volatility betas, the alphas decrease. The largest negative alpha results for the portfolio of stocks with the highest values for both $\beta_{j, t}^{\mathrm{V}}$ and $\beta_{j, t}^{\mathrm{Q}}$. For all volatility-of-volatility quintiles, we detect significantly negative alphas for the 5 minus 1 portfolios. The alphas range between $-13.7 \%$ and $-12.0 \%$ for equally weighted returns and are even larger in magnitude for value-weighted returns. Similarly, for all volatility quintiles, beside quintile 5 for value-weighted returns, we find significantly negative alphas for the 5 minus 1 portfolios. The alphas range between $-11.0 \%$ and $-8.0 \%$ for equally weighted returns and $-12.2 \%$ and $-6.4 \%$ for value-weighted returns. Consequently, as also indicated by the negative loading of the 5 minus 1 portfolio on aggregate volatility in Table 4, when controlling for aggregate volatility, the trade-off of volatility-of-volatility and returns is even more pronounced than for the univariate sorts.

In Panels $\mathrm{C}$ and $\mathrm{D}$ of Table 5, we report the results of double sorts of volatility-ofvolatility betas and betas with respect to the variance risk premium. For all quintiles of volatility-of-volatility betas, we find positive 5 minus 1 portfolio alphas on the variance risk premium. And for all variance risk premium beta quintiles, we detect a significantly negative hedge portfolio alpha for volatility-of-volatility. Bollerslev et al. (2009) find that the variance risk premium is associated with macroeconomic volatiltiy-of-volatility. In light of these results, one may argue that our result that both aggregate volatility-of-volatility and the market variance risk premium are priced is surprising. However, estimating the variance risk premium faces the problem of specifying an expectation of the variance under $\mathbb{P}$. Empirically, innovations in the market variance risk premium are mostly driven by innovations in the risk-neutral expectation. dVIX and dVRP are highly correlated with $-77 \%$. Hence, empirically, innovations in the market variance risk premium mostly capture innovations in 
aggregate volatility rather than consumption volatility-of-volatility. This suggests that it is important to directly use stock market volatility-of-volatility instead of simply following Bali \& Zhou (2015) in proxying consumption volatility-of-volatility with the market variance risk premium.

\section{Regression Tests}

The portfolio sorts present strong evidence that sensitivities to innovations in aggregate volatility-of-volatility are related to stock returns. The double sorts indicate that this relation persists when controlling for, and hence cannot be explained by, aggregate volatility or the variance risk premium. Following on from that, in this section, we estimate Fama \& MacBeth (1973) regressions that simultaneously control for different variables and test if a stock's sensitivity to innovations in aggregate volatility-of-volatility contains information about stock returns beyond that of various other firm characteristics and factor sensitivities. We perform the regressions using individual stocks instead of stock portfolios. Lo \& MacKinlay (1990) and Lewellen et al. (2010) argue against the use of portfolios in cross-sectional regressions, since the particular method, by which the portfolios are formed can severely influence the results. Furthermore, Ang et al. (2010) show that creating portfolios ignores important information on individual factor loadings and leads to higher asymptotic standard errors of risk premium estimates. Consequently, using individual stocks, we utilize this additional information and, at the same time, avoid the specification of breakpoints.

Each month, we perform cross-sectional regressions of stock excess returns over the following year on the stocks' sensitivities to innovations in aggregate volatility-of-volatility and several control variables, measured over the same period. We winsorize all regressors at the 1st and 99th percentile to restrict the effect of outliers (Fama \& French, 2008; Baltussen et al., 2015). ${ }^{18}$ For the regressions, we use ordinary least squares (equally weighted) or weighted least squares (value-weighted) with a diagonal weighting matrix, where the inverse of the firm's market value at the beginning of the estimation period for $\beta_{j, t}^{\mathrm{Q}}$ is along the

\footnotetext{
${ }^{18}$ The results of non-winsorized regression tests are qualitatively similar. These results are available upon request.
} 
diagonal, with the following regression equation:

$$
r_{j, t}-r_{f, t}=\lambda_{t}^{0}+\lambda_{t}^{\mathrm{M}} \beta_{j, t}^{\mathrm{M}}+\lambda_{t}^{\mathrm{V}} \beta_{j, t}^{\mathrm{V}}+\lambda_{t}^{\mathrm{Q}} \beta_{j, t}^{\mathrm{Q}}+\lambda_{t}^{\zeta} \beta_{j, t}^{\zeta}+\epsilon_{j, t} .
$$

$r_{j, t}$ is the annual return of stock $j$ and $r_{f, t}$ is the risk-free rate during that period. $\beta_{j, t}^{\mathrm{M}}$, $\beta_{j, t}^{\mathrm{V}}$, and $\beta_{j, t}^{\mathrm{Q}}$ are the stock's market beta, sensitivity to innovations in aggregate volatility and sensitivity to innovations in aggregate volatility-of-volatility over the evaluation period, respectively. The term $\beta_{j, t}^{\zeta}$ denotes a vector collecting further variables hypothesized to explain returns. $\lambda_{t}^{0}$ denotes the regression intercept and $\lambda_{t}^{\mathrm{M}}, \lambda_{t}^{\mathrm{V}}, \lambda_{t}^{\mathrm{Q}}$, and $\lambda_{t}^{\zeta}$ are the prices of factor risk associated with the respective variables. $\epsilon_{j, t}$ is the idiosyncratic return component of stock $j$ at time $t$.

In the next step, we perform tests on the time series averages $\overline{\lambda^{0}}, \lambda^{\bar{M}}, \lambda^{\mathrm{V}}, \overline{\lambda^{\mathrm{Q}}}$, and $\overline{\lambda^{\zeta}}$ of the estimated intercept and slope coefficients, $\hat{\lambda_{t}^{0}}, \lambda_{t}^{\mathrm{M}}, \hat{\lambda_{t}^{\mathrm{V}}}, \hat{\lambda_{t}^{\mathrm{Q}}}$, and $\hat{\lambda_{t}^{\zeta}}$. We account for potential autocorrelation, heteroskedasticity, and errors-in-variables concerns, computing robust Newey \& West (1987) (again using twelve lags) and Shanken (1992) adjusted p-values based on the time series of coefficient estimates.

Table 6 reports the results of the basic Fama \& MacBeth (1973) regressions. We report the results of a regression of excess returns on $\beta_{j, t}^{\mathrm{M}}, \beta_{j, t}^{\mathrm{V}}, \beta_{j, t}^{\mathrm{Q}}$, and various other canonical characteristics. In the basic regression specification suggested by our theoretical model (i), the price of risk on the market is essentially zero and the price of risk on aggregate volatility amounts to -0.2279 , which is significant at $5 \%$. The annual factor risk premium of aggregate volatility-of-volatility $\left(\lambda^{\bar{Q}}\right)$ is -0.7753 with a p-value of $0.010 .{ }^{19}$ Consequently, a two-standard deviation increase in a stock's volatility-of-volatility-sensitivity is associated with a $10.61 \%$ decrease in average annual returns. ${ }^{20}$

Adding further control variables, i.e., size, book-to-market, bid-ask spread, momentum, short-term reversal, age, and leverage in models (ii) to (viii) does not change our main results. The risk premium estimate on volatility-of-volatility remains economically large with values

\footnotetext{
${ }^{19}$ Note that the correlation between factor loadings on dVVIX and dVIX amounts to only $-40 \%$ (compared to the factor correlation of $67 \%$ ), which makes it unlikely that problems due to multicollinearity are present.

${ }^{20}$ This number is obtained as follows. We multiply the risk premium estimate with two times the average cross-sectional standard deviation of the sensitivities to innovations in aggregate volatility-of-volatility from Table $2(0.0684)$. Plugging in yields $-0.7735 *(2 * 0.0684)=-0.1061$.
} 
ranging from -0.81 to -0.70 and highly significant for every specification.

Adding all canonical characteristics jointly yields a factor risk premium of aggregate volatility-of-volatility of -0.69 , which is statistically significant at $5 \%$. The risk premium estimate on the market excess return is not significantly different from zero and even negative for some specifications. This result is consistent with recent evidence that market beta is not priced in the cross-section of stock returns (e.g., Frazzini \& Pedersen, 2014). Many of our control variables yield insignificant risk premium estimates for our sample period or conditional risk premium estimates with different signs compared to the previous literature. Hence, our results are in line with the view that prominent return anomalies have attenuated recently (Chordia et al., 2014). Adding characteristics univariately, we find a positive conditional risk premium on size and negative conditional risk premia on book-to-market and the bid-ask spread. Hence, stocks of large firms and stocks with lower bid-ask spreads, conditional on all remaining variables being the same, earn higher returns than stocks of small firms and stocks with higher bid-ask spreads and value stocks earn lower returns than growth stocks during the recent sample period. On the other hand, momentum, short-term reversal, age, and leverage do not obtain significant prices of risk, conditional on our main model specification.

Table A2 of the online appendix repeats the analysis for value-weighted regressions. The results are qualitatively similar. We obtain risk premium estimates on aggregate volatility-ofvolatility of around -0.8 , which are statistically significant at $5 \%$ throughout. Additionally, in Table A3 of the online appendix, we present the results when controlling for further returns distributions and liquidity-related characteristics, like idiosyncratic volatility, co-skewness, or Amihud illiquidity. For each of the model specifications, we obtain a significantly negative cross-sectional price of risk on aggregate volatility-of-volatility.

Lastly, we examine whether the cross-sectional regression results are consistent with the model predictions of Equation (13). The first model prediction is that the cross-sectional risk premium on the market portfolio is positive and proportional to the coefficient of relative riskaversion. For example, the coefficient of relative risk aversion in the basic model specification 
(i) of Table 6 is approximately equal to zero. ${ }^{21}$ The coefficient of relative risk aversion therefore is not really in a reasonable range (Friend \& Blume, 1975). For some specifications, the risk premium estimate on the market is even negative, implying a negative relative risk aversion. However, the standard error of the risk premium estimate on the market is typically large, e.g., it amounts to $6.26 \%$ in the basic model specification (i). Hence, the point estimate is ambiguous and has to be interpreted with caution. Next, we turn the focus on the price of risk on aggregate volatility, which is significantly negative throughout all test specifications. This is in line with the model's prediction. Finally, we find that the market price of risk on volatility-of-volatility, which could be positive or negative according to our theoretical model, is significantly negative. This result is consistent with Bali \& Zhou (2015), who proxy consumption volatility-of-volatility with the variance risk premium.

\section{Further Analyses}

\section{A Multivariate Estimation}

In this section, we examine the robustness of our results to jointly estimating the sensitivities to innovations in aggregate volatility-of-volatility with those to other factors, as presented in Equation (15). Table 7 reports the results of Fama \& MacBeth (1973) regressions using multivariate sensitivity estimation regressions. Incorporating the Fama \& French (1993) factors in model (i) leaves the risk premium estimate of aggregate volatilityof-volatility strongly significant at 1\%. Adding the other market factors like dSkew, dKurt, straddle vol, jump, or dVRP (models (ii) to (vii)) only marginally affects the risk premium estimate on aggregate volatility-of-volatility. It ranges from -0.76 to -0.71 and remains highly statistically significant. Adding the Hou et al. (2015b) factors in a joint sensitivity estimation, the risk premium estimate on aggregate volatility-of-volatility gets even more negative, reaching a value of -0.90 and is statistically significant at $1 \%$.

The price of risk on HML regularly is significantly negative, while that on MKT and SMB is never significantly different from zero. The prices of risk on jump is significantly negative

\footnotetext{
${ }^{21}$ The coefficient of relative risk aversion of the representative investor can be approximated by dividing the cross-sectional price of risk by the variance of the market return, which amounts to 0.0019.
} 
and those on straddle vol and dVRP are significantly positive. Regarding the new investment

and profitability factors of Hou et al. (2015b), ROE obtains a positive risk premium estimate while that on IA is indistinguishable from zero. The results for value-weighted regressions, presented in Table A4 of the online appendix, are qualitatively similar.

\section{B Orthogonalized Factor Innovations}

To account for concerns related to high correlations among market excess returns, innovations in the VIX, and innovations in the VVIX, this section reports results for orthogonalized factor innovations. We perform the orthogonalization following Sims (1980). We orthogonalize innovations in the VIX with respect to the market excess return and innovations in the VVIX with respect to both the market excess return and the VIX. With this order of orthogonalization, it is least likely that we find a positive market price of risk on aggregate volatility-of-volatility, since the common variation with the market excess return and aggregate volatility is removed from the variable.

The orthogonalization approach delivers two important insights. First, we can directly assess the market prices of risk on the factors which potentially deviate from the factor risk premia of a cross-sectional regression when the factors are strongly correlated. Second, we can test whether there is a clear incremental contribution of the information contained in aggregate volatility-of-volatility in explaining the cross-sectional variation in equity returns compared to only using the information contained in aggregate volatility and the market excess return.

The results are presented in Table 8 . We find that, consistent with the results presented in Table 6, the market price of risk on the market excess return is not significantly different from zero. The market price of risk on aggregate volatility is statistically significant at $1 \%$ in any case and is slightly smaller in magnitude compared to the non-orthogonalized version of Table 6 , with values ranging between -0.22 and -0.16 . Hence, the information contained in aggregate volatility has a strong marginal contribution in explaining the crosssection of stock returns relative to the market excess return. Finally, the market price of risk on the orthogonalized innovations in aggregate volatility-of-volatility ranges between -0.41 and -0.35 . The market price of risk of the orthogonalized factor innovations is only about 
half that of the non-orthogonalized innovations. Hence, as indicated by the correlation of innovations in volatility-of-volatility with those in volatility as well as the market excess return, there seems to be some interaction of these factors. However, the market price of risk on the orthogonalized aggregate volatility-of-volatility is still significant with p-values ranging between $3.7 \%$ and $8.8 \%$. For model specification (i), a two standard deviation increase in factor loadings on orthogonalized volatility-of-volatility innovations is associated with a decrease in annual returns of about 5.2\%. Consequently, we find compelling evidence that volatility-of-volatility is a priced risk factor in the cross-section of equity returns, over and above aggregate volatility.

\section{Predicting Future Factor Loadings}

In Section IV, we demonstrate a strong negative relation between the contemporaneous sensitivities to innovations in aggregate volatility-of-volatility and stock returns. While the previous analysis strongly indicates that volatility-of-volatility is a priced risk factor, for practical purposes it is also of interest how this risk can be hedged. Therefore, in this section, we first examine whether one can create the same return spread using pre-formation factor loadings. In the second part of this section, we examine which past sensitivities and stock characteristics best predict future volatility-of-volatility sensitivities.

We start by examining the relation of average returns and past sensitivities to innovations in aggregate volatility-of-volatility. Ang et al. (2006a) point out that pre-formation factor loadings, beside actual variation in exposures toward that factor, additionally reflect measurement error. This measurement error is likely to be especially high during highly volatile times, like, in particular, in the first part of our sample period. Taken together, noisy estimates of our sorting variable and a relatively short sample increase the standard error estimates and yield a test with reduced statistical power to detect significant spreads in returns and alphas. Hence, while for these reasons we concentrate on the results generated using post-formation factor loadings, the results from pre-formation factor loadings might be weaker than those presented in the previous sections.

Table 9 reports these results. Sorting the stocks by past exposure to aggregate volatilityof-volatility fails to produce any spread in average returns and Hou et al. (2015b) factor 
alphas. The main explanation for this is given by the realized ex post factor sensitivities of the portfolios. In the presence of higher measurement errors, the spread in ex post exposures to aggregate volatility-of-volatility is only 0.002 for equally weighted portfolios and even negative with -0.006 for value-weighted portfolios. This spread is substantially smaller than the 0.13 produced by sorting on contemporaneous factor loadings (see Table 4). Hence, the current factor loadings on average have very weak predictability for future factor loadings in aggregate volatility-of-volatility.

Given the weak results when using pre-formation factor loadings, we examine the crosssectional predictability of several ex ante firm characteristics and factor sensitivities for future sensitivities to innovations in aggregate volatility-of-volatility by performing Fama \& MacBeth (1973) regressions. Cross-sectional predictors of the stocks' volatility-of-volatilitysensitivities are measured during the twelve months directly prior to the twelve-month estimation period for sensitivities to innovations in aggregate volatility-of-volatility. The results are reported in Table 10. Consistent with the results for the pre-formation factor loadings in Table 9, we find that past volatility-of-volatility-sensitivities do not significantly predict future relative volatility-of-volatility-sensitivities. ${ }^{22}$ Hence, there appears to be large timevariation in factor loadings on aggregate volatility-of-volatility. The best predictors for future volatility-of-volatility factor sensitivities are past beta with a positive sign and the bid-askspread, momentum, short-term reversal, idiosyncratic volatility, and downside beta with a negative sign. The adjusted $\mathrm{R}^{2}$, however, is only $8.3 \%$ when including all predictors. Hence, although we find some characteristics that are related to future volatility-of-volatility factor loadings, it is difficult to predict future factor loadings and hedge volatility-of-volatility risk in the stock market. ${ }^{23}$

\section{Hedging Volatility-of-Volatility Risk}

The preceeding sections show that volatility-of-volatility is sigificantly priced in the stock market but difficult to hedge. In this section, we examine the VIX options market that likely

\footnotetext{
${ }^{22}$ We find that the factor loadings on the VIX are slightly better predictable than those on the VVIX, but not very much. The average 12-month autocorrelation of VIX factor loadings $7.4 \%$.

${ }^{23}$ We experimented with various possibilities to predict future volatility-of-volatility factor loadings. However, we could not create a significant spread in returns using these predictors.
} 
delivers better hedging opportunities. ${ }^{24}$ Since the vega, i.e., the sensitivity of the options price with respect to the volatility of the unerlying, of all options is positive, these are natural instruments to hedge against increases in the volatility of the underlying. We follow Bakshi \& Kapadia (2003) and Huang \& Shaliastovich (2014), computing continuously-rebalanced delta-hedged option returns. The delta-hedged VIX-option position is approximately insensitive to innovations in aggregate volatility. Hence, it only delivers insurance against increases in aggregate volatility-of-volatility. The option gain can be computed as follows (Huang \& Shaliastovich, 2014):

$$
\Pi_{t, T}=M_{T}-M_{t}-\sum_{\tau=0}^{N-1} \Delta_{t_{\tau}}\left(F_{\tau+1}-F_{\tau}\right)-\sum_{\tau=0}^{N-1} r_{f, \tau} M_{t} \frac{T-t}{N} .
$$

$\Pi_{t, T}$ is the option gain and $F_{t}$ is the forward price of the option's underlying. We divide $\Pi_{t, T}$ by the forward price $F_{t}$ to obtain the delta-hedged return on the option. $M_{T}$ is the final payoff of the option (put or call) at time $T$ and $M_{t}$ is the option price at initiation $t . \Delta_{t_{\tau}}$ is the Black \& Scholes (1973) delta of the option at time $\tau$. $N$ is the number of days between $t$ and $T$ that are trading days. All other variables are as previously defined. We use all options with volume and open interest greater than zero. For the strategy, we buy options with 30 days to maturity and hold them until expiration, rebalancing the delta-hedge at the end of each trading day.

We present the results for delta-hedged option returns in Table 11. Consistent with Huang \& Shaliastovich (2014), who end their sample period in September 2012, we find negative delta-hedged option returns both for calls and puts for each moneyness bin, with moneyness computed as strike price over futures price at initiation $\left(\frac{K}{F_{t}}\right)$, between 0.7 and 1.3. These returns are significantly negative for in-the-money calls and both in-the-money and out-of-the-money puts. This finding confirms our previous results of a negative risk premium on volatility-of-volatility. On average, investors on the options market are also willing to pay a premium in order to insure against increases in aggregate volatility-of-volatility. Worth noting are also the distributional characteristics of the delta-hedged option returns. The returns are highly positively skewed with skewness of 0.74 up to 1.68 and have high kurtosis

\footnotetext{
${ }^{24}$ We thank an anonymous referee for suggesting this.
} 
between 8.36 and 9.13. The $5 \%$ quantile of option return lies between $-4.8 \%$ and $-2.0 \%$ for the different moneyness bins. The $95 \%$ quantile lies between $1.3 \%$ and $7.8 \%$. Hence, the option return can become strongly positive. These distributional characteristics further indicate that the options on the VIX are adequate hedges for volatility-of-volatility risk. ${ }^{25}$

\section{E Realized Measure of Aggregate Volatility-of-Volatility}

Taking account of the literature on volatility estimation, we further test the robustness of our results employing an inferior measure of aggregate volatility-of-volatility. Instead of utilizing the forward-looking expected volatiltiy-of-volatiltiy, in this section, we rely on the realized volatility of the VIX. To perform the analysis, we use five-minute high-frequency data on the VIX from the TRTH database and estimate each day the realized bipower volatility over the past month (Barndorff-Nielsen \& Shephard, 2004). Since the high-frequency data is available for a longer period, we extend the sample period to January 01, 2000 until September 30, 2016. We perform standard data cleaning operations following BarndorffNielsen et al. (2009). Following on from that, we obtain daily realized volatilities of the VIX and compute the innovations $\left(d V o V I X_{t}\right)$ again as simple first differences. We estimate factor sensitivities using Equation (14), replacing dVVIX by dVoVIX.

We present the results of portfolio sorts based on dVoVIX in Table A5 of the online appendix. The return differential between stocks with high and those with low sensitivities to innovations in aggregate volatility-of-volatility is only slightly smaller than when using the VVIX in Table 4 with about $-3.4 \%$. The return differential is not significant with a p-value of 0.19. However, once controlling for systematic risk, we find a significant volatilityof-volatility-return trade-off with alphas relative to the CAPM, 4-factor, and 5-factor models of $-6.6 \%$ up to $-4.4 \%$ which are all significant. When using the Hou et al. (2015b) factor model, the alpha becomes insignificant. When restricting the sample to the horizon in which data on the VVIX is available (2006 until 2016), we also do not find a significant return differential but a significant Hou et al. (2015b) alpha.

Even though the portfolio of stocks with high sensitivities to innovations in aggregate

\footnotetext{
${ }^{25}$ Huang \& Shaliastovich (2014) further show that volatility-of-volatility can predict future delta-hedged option returns.
} 
volatility-of-volatility has highly significantly negative alphas in most cases, these are not directly carried over to the hedge portfolio since the alpha of the portfolio with the lowest sensitivities is close to zero or also slightly negative on average. Hence, overall the model prediction that investors strongly demand stocks which insure against increases in aggregate volatility-of-volatility is confirmed by these results. However, using a realized measure of volatility-of-volatility, the monotonicity in portfolios 1 to 4 vanishes. Consequently, when using this theoretically inferior measure, there is still some indication of a volatility-ofvolatility-return trade-off, but this result is less significant and also less robust. Therefore, it is important to use the forward-looking information from options markets. ${ }^{26}$

\section{Conclusion}

Using a simple stylized theoretical model with Epstein-Zin preferences and consumption uncertainty, we motivate a potential trade-off of volatility-of-volatility and stock returns. In our empirical study, we confirm this model prediction. We find that aggregate volatility-ofvolatility carries a considerable and robust negative risk premium.

We use both uni- and bivariate portfolio sorts and show that the quintile portfolio of stocks with the highest sensitivity toward innovations in aggregate volatility-of-volatility underperforms the quintile of stocks with the lowest exposure to aggregate volatility-ofvolatility by about $5 \%$ per annum. Using regression tests, we estimate the cross-sectional price of factor risk of aggregate volatility-of-volatility to be both economically substantial and statistically highly significant. The estimated factor price on aggregate volatility-ofvolatility cannot be explained by known risk factors. Our results are also consistent with any multi-factor model, in which aggregate volatility-of-volatility is priced with a negative sign if investors relate a positive change in aggregate volatility-of-volatility to future unfavorable shifts in the investment opportunity set.

\footnotetext{
${ }^{26}$ This result is similar to that of Ang et al. (2006b), who only find a significant spread in the cross-section of returns when using an option-implied, as opposed to a simple historical or high-frequency, measure to proxy for innovations in aggregate volatility.
} 


\section{Appendix}

\section{A Variable Definitions - Main Control Variables}

- Age (Zhang, 2006) is the number of years up to time $t$ since a firm first appeared in the CRSP database. In regressions, we take the natural logarithm to remove the extreme skewness in this variable.

- Aggregate volatility (Ang et al., 2006b, "dVIX"), is the coefficient $\beta_{j, t}^{V}$ obtained by the regression in Equation (14).

- Beta is the coefficient $\beta_{j, t}^{M}$ obtained by the regression in Equation (14).

- Bid-ask spread is the stock's average daily relative bid-ask spread over the examination period.

- Book-to-market (Fama \& French, 1992) is the weighted average of book equity divided by market equity over the examination period. Book and market equity are updated every 12 months for the beginning of the year. Book equity is defined as stockholders' equity, plus balance sheet deferred taxes and investment tax credit, plus post-retirement benefit liabilities, minus the book value of preferred stock.

- Leverage (Bhandari, 1988) is defined as the weighted average of one minus book equity (see "Book-to-market") divided by total assets (Compustat: AT). Book equity and total assets are updated every 12 months for the beginning of the year.

- Market factors: "MKT" is the value-weighted excess return on all CRSP firms. "SMB", and "HML" are the Fama \& French (1993) size and value factors. "SMB ${ }^{H X Z ",}$ "IA", and "ROE" are the size, investment, and profitability factors of Hou et al. (2015b).

- Market variance risk premium (Han \& Zhou, 2012, "dVRP"), is the coefficient $\beta_{j, t}^{d V R P}$ in the regression $r_{j, \tau}-r_{f, \tau}=\alpha_{j, t}+\beta_{j, t}^{M}\left(r_{M, \tau}-r_{f, \tau}\right)+\beta_{j, t}^{d V R P} d V R P_{\tau}+\epsilon_{j, \tau}$, using daily returns over the examination period (Ang et al., 2006a), where the market variance risk premium is defined as the difference between the physical expected variance 
and the risk-neutral expected variance $\left(V I X^{2}\right)$ of the S\&P 500 index over a 30-day horizon using daily return data. First, we compute the expected variance $\left(E V_{\tau}\right)$ under the physical measure by regressing the annualized realized variance $\left(R V_{\tilde{\tau}+30}\right)$ on the lagged implied $\left(V I X_{\tilde{\tau}}^{2}\right)$ and the lagged annualized historical $\left(R V_{\tilde{\tau}}\right)$ realized variance, using an expanding window of daily data that is available at time $\tau$, starting with data from January 01, 1996 ( $\tilde{\tau}$ refers to those dates) $R V_{\tilde{\tau}+30}=\alpha_{\tau}+\beta_{\tau} V I X_{\tilde{\tau}}^{2}+\gamma_{\tau} R V_{\tilde{\tau}}+\epsilon_{\tilde{\tau}+30}$ in a first step and then computing $E V_{\tau}=\hat{\alpha}_{\tau}+\hat{\beta}_{\tau} V I X_{\tau}^{2}+\hat{\gamma}_{\tau} R V_{\tau}$. The market variance risk premium $\left(\mathrm{VRP}_{\tau}\right)$ is obtained as $V R P_{\tau}=E V_{\tau}-V I X_{\tau}^{2}$. dVRP is obtained as the first difference in VRP.

- Momentum (Jegadeesh \& Titman, 1993) is the cumulative stock return over the period from $t-12$ until $t-1$.

- Short-term reversal (Jegadeesh, 1990) is the preceding month's stock return (from $t-1$ to $t)$.

- Size (Banz, 1981) is the average of firm's market capitalization over the examination period. Market capitalization is computed as the product of the price times the number of shares outstanding. In regressions, we take the natural logarithm to remove the extreme skewness in this variable.

- Stochastic volatility (Cremers et al., 2015, "straddle vol"), market skewness and kurtosis (Chang et al., 2013, "dSkew", "dKurt"), and aggregate jump risk (Cremers et al., 2015, "jump") are the coefficients $\beta_{j, t}^{F}$ in the regression $r_{j, \tau}-r_{f, \tau}=\alpha_{j, t}+\beta_{j, t}^{M}\left(r_{M, \tau}-\right.$ $\left.r_{f, \tau}\right)+\beta_{j, t}^{F} F_{\tau}+\epsilon_{j, \tau}$, using daily returns over the examination period (Ang et al., 2006a), where $F$ is one of the following:

- Innovations in implied market skewness and kurtosis (Chang et al., 2013), which are defined as the difference of daily implied skewness (kurtosis) computed from S\&P 500 index options using the formulas of Bakshi et al. (2003) and its expectation, which is obtained by fitting an $\operatorname{ARMA}(1,1)$ model on the complete time series of skewness (kurtosis) estimates. The resulting measure of innovations in market skewness then is $d S k e w_{\tau}=S k e w_{\tau}-0.9993 S k e w_{\tau-1}+0.6647 d S k e w_{\tau-1}$ 
and that of innovations in market kurtosis is $d K_{u r t}=$ Kurt $_{\tau}-0.9999$ Kurt $_{\tau-1}+$ $0.4971 d$ Kurt $_{\tau-1}$.

- Market-neutral straddle returns (Cremers et al., 2015) are computed by first constructing at-the-money zero beta straddles. Afterwards, the straddle vol factor is the return of a gamma neutral and vega positive portfolio of the two straddles maturing in the next month and the month after next, while the jump factor is the return of a gamma positive and vega neutral portfolio using the same straddles. To construct the factors, we use Black \& Scholes (1973) option sensitivities.

\section{B Variable Definitions - Further Controls}

- Amihud illiquidity (Amihud, 2002) is the absolute value of the stock's return divided by the daily dollar volume, averaged over the examination period. Specifically, it is $I l l i q_{t}=\frac{1}{n} \sum_{\tau=1}^{n} \frac{\left|r_{j, \tau}\right|}{{\text { Volume } \$_{\tau}}_{1}}$, with the daily dollar volume (Volume $\$_{\tau}$, in thousand dollars) being calculated as last trade price times shares traded on day $\tau$, while the summation is taken over all $n$ trading days during the examination period.

- Co-Skewness (Harvey \& Siddique, 2000) and Co-Kurtosis (Dittmar, 2002) are the coefficients $\beta_{j, t}^{C S}$ and $\beta_{j, t}^{C K}$ in the regression $r_{j, \tau}-r_{f, \tau}=\alpha_{j, t}+\beta_{j, t}^{M}\left(r_{M, \tau}-r_{f, \tau}\right)+\beta_{j, t}^{C S}\left(r_{M, \tau}-\right.$ $\left.r_{f, \tau}\right)^{2}+\beta_{j, t}^{C K}\left(r_{M, \tau}-r_{f, \tau}\right)^{3}+\epsilon_{j, \tau}$, including the market excess return, the squared market excess return, and the cubed market excess return. The regression is estimated using daily returns over the examination period.

- Demand for lottery (Bali et al., 2011, "MAX") is the average of the five highest daily returns during the examination period.

- Downside beta (Ang et al., 2006a) is the coefficient $\beta_{j, t}^{D}$ in the regression $r_{j, \tau}-r_{f, \tau}=$ $\alpha_{j, t}+\beta_{j, t}^{D}\left(r_{M, \tau}-r_{f, \tau}\right)+\epsilon_{j, \tau}$, using daily returns over the examination period only when the market return is below the average daily market return over that year.

- Idiosyncratic volatility (Ang et al., 2006b, "idio. volatility") is the standard deviation of the residuals $\epsilon_{j, \tau}$ in the Fama \& French (1993) 3 -factor model $r_{j, \tau}-r_{f, \tau}=$ 
$\alpha_{j, t}+\beta_{j, t}^{M}\left(r_{M, \tau}-r_{f, \tau}\right)+\beta_{j, t}^{S} S M B_{\tau}+\beta_{j, t}^{H} H M L_{\tau}+\epsilon_{j, \tau}$, using daily returns over the examination period. $S M B_{\tau}$ and $H M L_{\tau}$ denote the returns on the Fama \& French (1993) factors.

- Kurtosis is the stock's scaled fourth moment, computed using daily returns over the examination period.

- Pastor-Stambough liquidity (Pastor \& Stambaugh, 2003, "PS liquidity") is the coefficient $\beta_{j, t}^{L}$ in the following regression $r_{j, \tau}-r_{f, \tau}=\alpha_{j, t}+\beta_{j, t}^{M}\left(r_{M, \tau}-r_{f, \tau}\right)+\beta_{j, t}^{S} S M B_{\tau}+$ $\beta_{j, t}^{H} H M L_{\tau}+\beta_{j, t}^{L} L_{\tau}+\epsilon_{j, \tau}$, where $L_{\tau}$ is the liquidity factor provided by Lubos Pastor and $r_{M, \tau}-r_{f, \tau}=M K T_{\tau}, S M B_{\tau}$, and $H M L_{\tau}$ are the Fama-French factors provided by Kenneth R. French. We run the regression using the monthly returns during the examination period.

- Skewness $(\mathrm{Xu}, 2007)$ is the stock's scaled third moment computed using daily returns over the examination period.

- Turnover (Datar et al., 1998) is the number of shares traded in one month divided by the total shares outstanding, averaged over all months in the examination period.

- Volatility (Zhang, 2006) is the stock's standard deviation computed using daily returns over the examination period.

- Volume (Gervais et al., 2001) is the stock's average daily dollar trading volume over the examination period. In regressions, we take the natural logarithm to remove the extreme skewness in this variable. 


\section{References}

Adrian, T., \& Rosenberg, J. (2008). Stock returns and volatility: Pricing the short-run and long-run components of market risk. Journal of Finance, 63(6), 2997-3030.

Amihud, Y. (2002). Illiquidity and stock returns: Cross-section and time-series effects. Journal of Financial Markets, 5(1), 31-56.

Ang, A., Chen, J., \& Xing, Y. (2006a). Downside risk. Review of Financial Studies, 19(4), 1191-1239.

Ang, A., Hodrick, R. J., Xing, Y., \& Zhang, X. (2006b). The cross-section of volatility and expected returns. Journal of Finance, 61(1), 259-299.

Ang, A., Liu, J., \& Schwarz, K. (2010). Using stocks or portfolios in tests of factor models. Working Paper, Columbia University and University of Pennsylvania.

Bakshi, G., \& Kapadia, N. (2003). Delta-hedged gains and the negative market volatility risk premium. Review of Financial Studies, 16(2), 527-566.

Bakshi, G., Kapadia, N., \& Madan, D. (2003). Stock return characteristics, skew laws, and the differential pricing of individual equity options. Review of Financial Studies, 16(1), $101-143$.

Bali, T., \& Zhou, H. (2015). Risk, uncertainty, and expected returns. Journal of Financial and Quantitative Analysis, forthcoming.

Bali, T. G., Cakici, N., \& Whitelaw, R. F. (2011). Maxing out: Stocks as lotteries and the cross-section of expected returns. Journal of Financial Economics, 99(2), 427-446.

Baltussen, G., Van Bekkum, S., \& Van Der Grient, B. (2015). Unknown unknowns: Uncertainty about risk and stock returns. Journal of Financial and Quantitative Analysis, forthcoming.

Bansal, R., \& Yaron, A. (2004). Risks for the long run: A potential resolution of asset pricing puzzles. Journal of Finance, 59(4), 1481-1509.

Banz, R. W. (1981). The relationship between return and market value of common stocks. Journal of Financial Economics, 9(1), 3-18.

Barndorff-Nielsen, O. E., Hansen, P. R., Lunde, A., \& Shephard, N. (2009). Realized kernels in practice: Trades and quotes. Econometrics Journal, 12(3), 1-32.

Barndorff-Nielsen, O. E., \& Shephard, N. (2004). Power and bipower variation with stochastic volatility and jumps. Journal of Financial Econometrics, 2(1), 1-37.

Barndorff-Nielsen, O. E., \& Veraart, A. E. (2012). Stochastic volatility of volatility and variance risk premia. Journal of Financial Econometrics, 11(1), 1-46. 
Bhandari, L. C. (1988). Debt/equity ratio and expected common stock returns: Empirical evidence. Journal of Finance, 43(2), 507-528.

Black, F., Jensen, M., \& Scholes, M. (1972). The capital asset pricing model: Some empirical tests. In M. Jensen (Ed.) Studies in the Theory of Capital Markets, (pp. 79-121). New York: Praeger.

Black, F., \& Scholes, M. (1973). The pricing of options and corporate liabilities. Journal of Political Economy, 81(3), 637-654.

Bollerslev, T., Tauchen, G., \& Zhou, H. (2009). Expected stock returns and variance risk premia. Review of Financial Studies, 22(11), 4463-4492.

Campbell, J. Y., Giglio, S., Polk, C., \& Turley, R. (2014). An intertemporal CAPM with stochastic volatility. Harvard University Working Paper.

Campbell, J. Y., \& Shiller, R. J. (1988). The dividend-price ratio and expectations of future dividends and discount factors. Review of Financial Studies, 1(3), 195-228.

Carhart, M. M. (1997). On persistence in mutual fund performance. Journal of Finance, 52(1), 57-82.

Chang, B. Y., Christoffersen, P., \& Jacobs, K. (2013). Market skewness risk and the cross section of stock returns. Journal of Financial Economics, 107(1), 46-68.

Chen, N.-F., Roll, R., \& Ross, S. A. (1986). Economic forces and the stock market. Journal of Business, 59(3), 383-403.

Chen, T.-F., Chung, S.-L., \& Lin, J.-C. (2014). Volatility-of-volatility risk and asset prices. $L S U$ Working Paper.

Chordia, T., Subrahmanyam, A., \& Tong, Q. (2014). Have capital market anomalies attenuated in the recent era of high liquidity and trading activity? Journal of Accounting and Economics, 58(1), 41-58.

Cremers, K., Halling, M., \& Weinbaum, D. (2015). Aggregate jump and volatility risk in the cross-section of stock returns. Journal of Finance, 70(2), 577-614.

Datar, V. T., Y Naik, N., \& Radcliffe, R. (1998). Liquidity and stock returns: An alternative test. Journal of Financial Markets, 1(2), 203-219.

D'Avolio, G. (2002). The market for borrowing stock. Journal of Financial Economics, $66(2), 271-306$.

Dittmar, R. F. (2002). Nonlinear pricing kernels, kurtosis preference, and evidence from the cross section of equity returns. Journal of Finance, (pp. 369-403).

Epstein, L. G., \& Ji, S. (2013). Ambiguous volatility and asset pricing in continuous time. Review of Financial Studies, 26(7), 1740-1786. 
Epstein, L. G., \& Zin, S. E. (1989). Substitution, risk aversion, and the temporal behavior of consumption and asset returns: A theoretical framework. Econometrica, 57(4), 937-969.

Epstein, L. G., \& Zin, S. E. (1991). Substitution, risk aversion, and the temporal behavior of consumption and asset returns: An empirical analysis. Journal of Political Economy, $99(2), 263-286$.

Fabozzi, F. J., Huang, D., \& Wang, J. (2016). What difference do new factor models make in portfolio allocation? EDHEC Working Paper.

Fama, E. F., \& French, K. R. (1992). The cross-section of expected stock returns. Journal of Finance, $47(2), 427-465$.

Fama, E. F., \& French, K. R. (1993). Common risk factors in the returns on stocks and bonds. Journal of Financial Economics, 33(1), 3-56.

Fama, E. F., \& French, K. R. (2008). Dissecting anomalies. Journal of Finance, 63(4), $1653-1678$.

Fama, E. F., \& French, K. R. (2015). A five-factor asset pricing model. Journal of Financial Economics, 116(1), 1-22.

Fama, E. F., \& MacBeth, J. D. (1973). Risk, return, and equilibrium: Empirical tests. Journal of Political Economy, 81(4), 607-636.

Frazzini, A., \& Pedersen, L. H. (2014). Betting against beta. Journal of Financial Economics, $111(1), 1-25$.

Friend, I., \& Blume, M. E. (1975). The demand for risky assets. American Economic Review, $65,900-922$.

Gervais, S., Kaniel, R., \& Mingelgrin, D. H. (2001). The high-volume return premium. Journal of Finance, 56(3), 877-919.

Han, B., \& Zhou, Y. (2012). Variance risk premium and cross-section of stock returns. University of Texas at Austin Working Paper.

Harvey, C. R., \& Siddique, A. (2000). Conditional skewness in asset pricing tests. Journal of Finance, $55(3), 1263-1295$.

Hou, K., Xue, C., \& Zhang, L. (2015a). A comparison of new factor models. Ohio State University Working Paper.

Hou, K., Xue, C., \& Zhang, L. (2015b). Digesting anomalies: An investment approach. Review of Financial Studies, 28(3), 650-705.

Huang, D., \& Shaliastovich, I. (2014). Volatility of volatility risk. University of Pennsylvania Working Paper. 
Jegadeesh, N. (1990). Evidence of predictable behavior of security returns. Journal of Finance, 45(3), 881-898.

Jegadeesh, N., \& Titman, S. (1993). Returns to buying winners and selling losers: Implications for stock market efficiency. Journal of Finance, 48(1), 65-91.

Jiang, G. J., \& Tian, Y. S. (2005). The model-free implied volatility and its information content. Review of Financial Studies, 18(4), 1305-1342.

Lettau, M., Maggiori, M., \& Weber, M. (2014). Conditional risk premia in currency markets and other asset classes. Journal of Financial Economics, 114(2), 197-225.

Lewellen, J., Nagel, S., \& Shanken, J. (2010). A skeptical appraisal of asset pricing tests. Journal of Financial Economics, 96(2), 175-194.

Lo, A. W., \& MacKinlay, A. C. (1990). Data-snooping biases in tests of financial asset pricing models. Review of Financial Studies, 3(3), 431-467.

Merton, R. C. (1980). On estimating the expected return on the market: An exploratory investigation. Journal of Financial Economics, 8(4), 323-361.

Newey, W. K., \& West, K. D. (1987). A simple, positive semi-definite, heteroskedasticity and autocorrelation consistent covariance matrix. Econometrica, 55(3), 703-708.

Novy-Marx, R. (2013). The other side of value: The gross profitability premium. Journal of Financial Economics, 108(1), 1-28.

Pastor, L., \& Stambaugh, R. F. (2003). Liquidity risk and expected stock returns. Journal of Political Economy, 111(3), 642-685.

Prokopczuk, M., \& Wese Simen, C. (2014). The importance of the volatility risk premium for volatility forecasting. Journal of Banking \& Finance, 40, 303-320.

Shanken, J. (1992). On the estimation of beta-pricing models. Review of Financial Studies, $5(1), 1-55$.

Shumway, T. (1997). The delisting bias in CRSP data. Journal of Finance, 52(1), 327-340.

Shumway, T., \& Warther, V. A. (1999). The delisting bias in CRSP's NASDAQ data and its implications for the size effect. Journal of Finance, 54(6), 2361-2379.

Sims, C. A. (1980). Macroeconomics and reality. Econometrica, 48, 1-48.

Xu, J. (2007). Price convexity and skewness. Journal of Finance, 62(5), 2521-2552.

Zhang, X. (2006). Information uncertainty and stock returns. Journal of Finance, 61(1), $105-137$. 


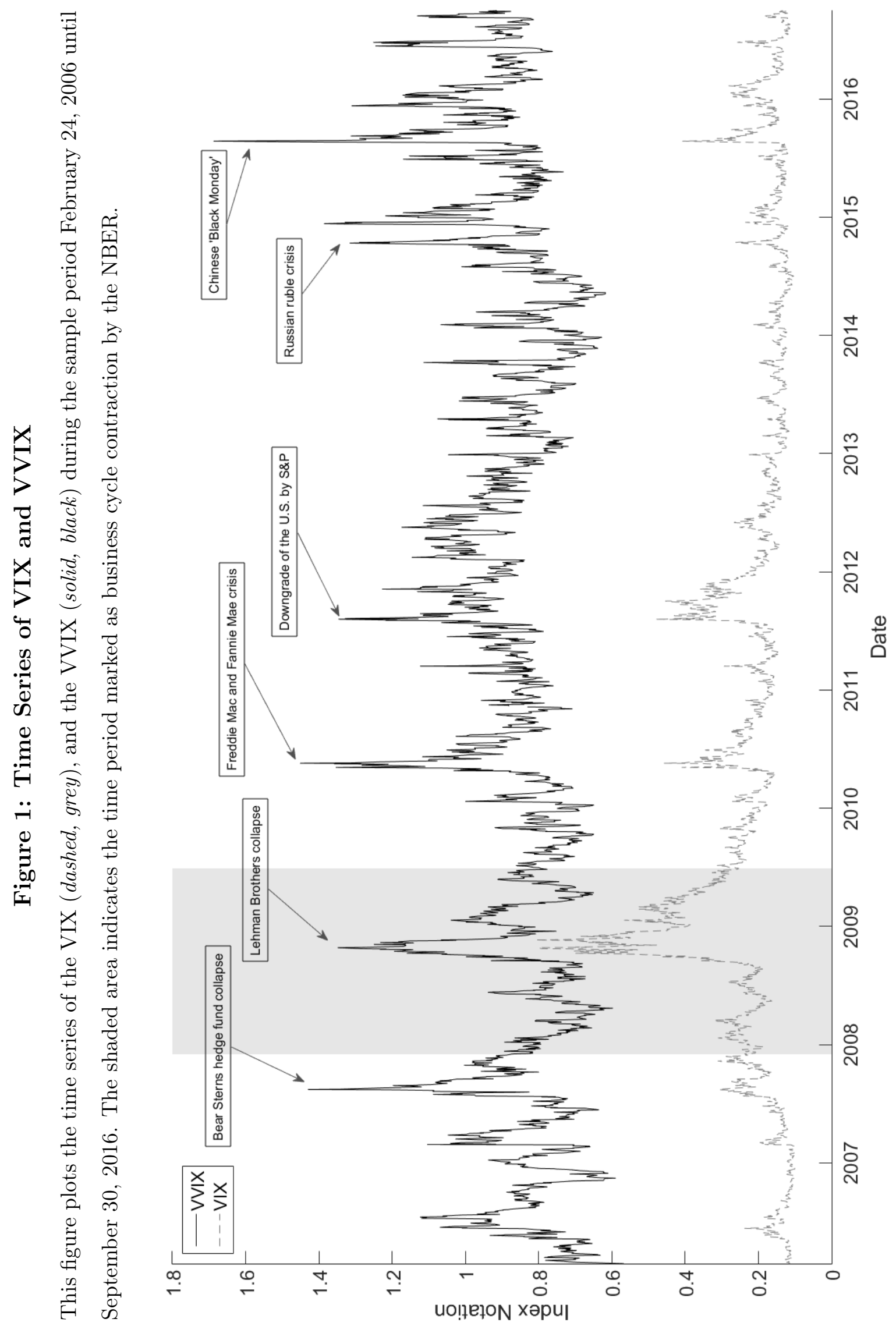



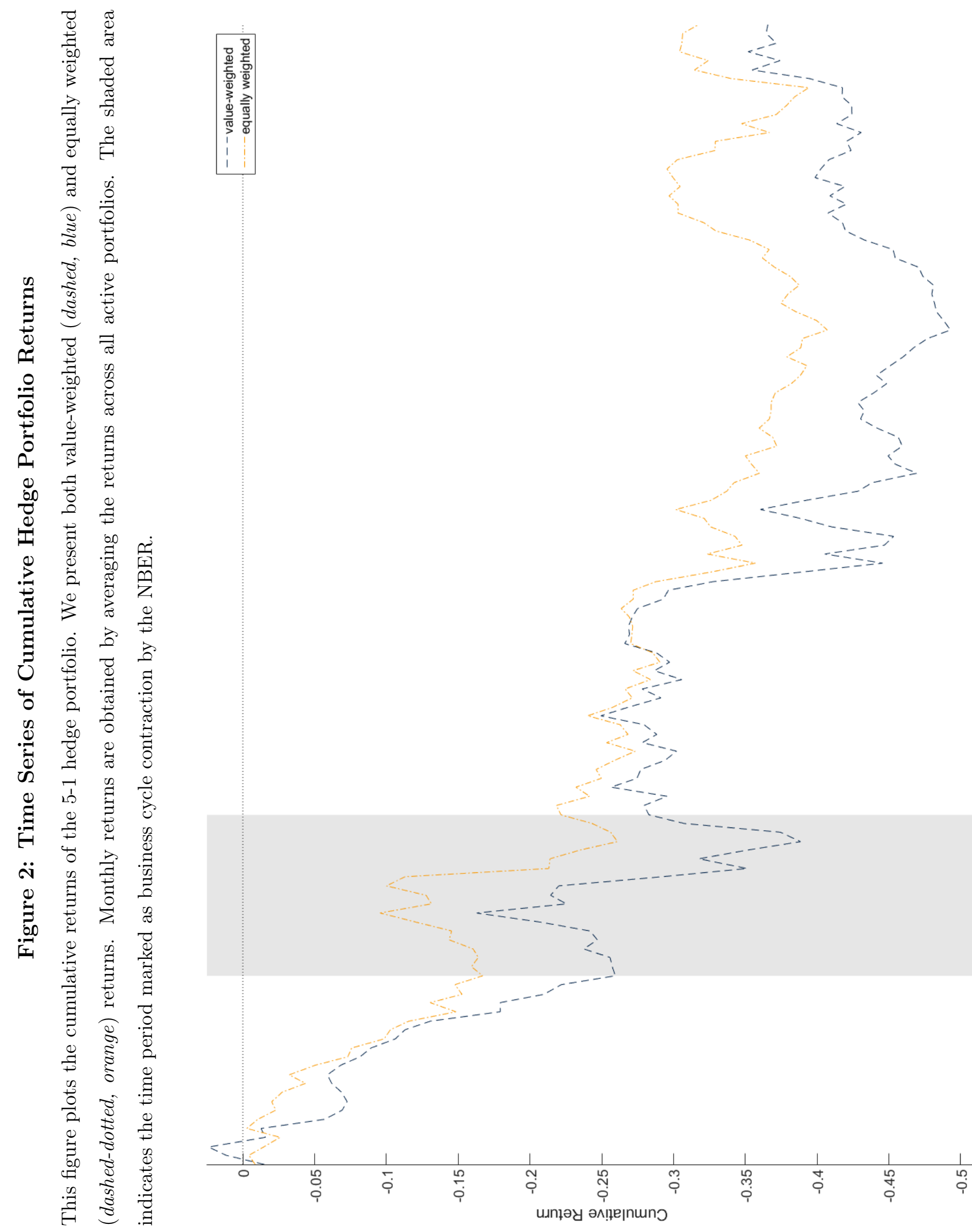

$-\frac{N}{2}$

$\frac{1}{\pi}$

호

울

응

ㅇํํ 


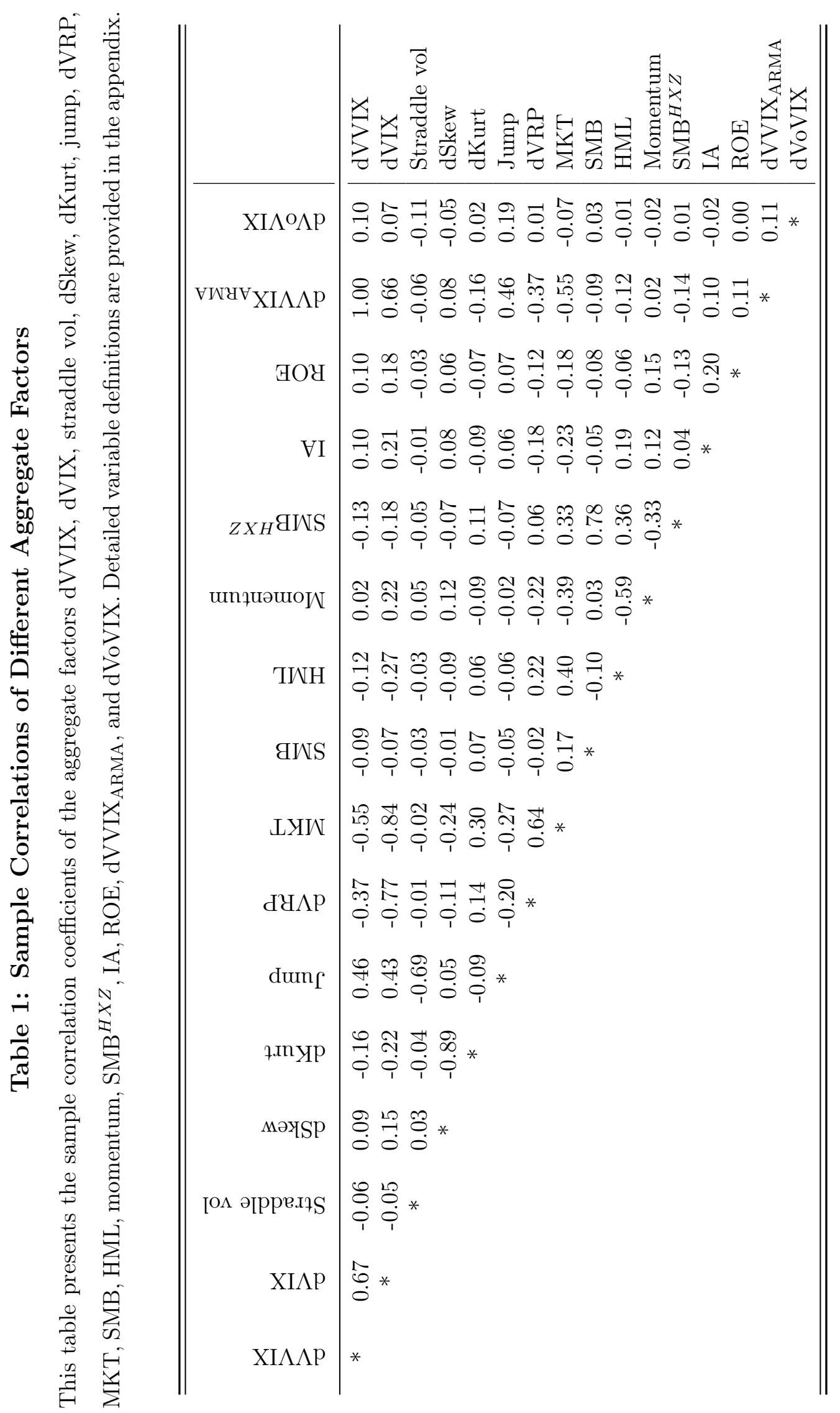




\section{Table 2: Summary Statistics}

Panel A of this table presents summary statistics on the aggregate factors dVVIX, dVIX, straddle vol, dSkew, dKurt, jump, dVRP, MKT, SMB, HML, momentum, SMB ${ }^{H X Z}$, IA, ROE, dVVIX ARMA, and dVoVIX. Detailed variable definitions are provided in the appendix. Panel B provides yearly summary statistics on the VVIX and Panel C shows yearly summary statistics on the individual stocks' sensitivities to aggregate volatility-of-volatility, $\beta^{\mathrm{Q}}$, with the sensitivity estimation starting in the year denoted first in the first column. Mean, Median, and Std. dev. refer to the sample average, median, and standard deviation of the factors, respectively. P10 and P90 refer to the 10\% and $90 \%$ percentiles, respectively. AR(1) indicates the first order autocorrelation.

Panel A: Market Factors

\begin{tabular}{lcccccc}
\hline \hline Variable & Mean & Median & Std. dev. & AR $(1)$ & P10 & P90 \\
\hline dVVIX & 0.00011 & -0.00350 & 0.0471 & -0.0838 & -0.0471 & 0.0511 \\
dVIX & 0.00001 & -0.00095 & 0.0192 & -0.1284 & -0.0170 & 0.0175 \\
Straddle vol & -0.00014 & 0.00109 & 0.0158 & -0.0408 & -0.0166 & 0.0156 \\
dSkew & -0.00228 & -0.00351 & 0.0790 & 0.2265 & -0.0969 & 0.0896 \\
dKurt & 0.00109 & -0.00232 & 0.1205 & 0.1339 & -0.1369 & 0.1454 \\
Jump & -0.00171 & -0.00962 & 0.0557 & -0.0953 & -0.0447 & 0.0428 \\
dVRP & 0.00000 & -0.00002 & 0.0086 & -0.0379 & -0.0039 & 0.0037 \\
MKT & 0.00033 & 0.00080 & 0.0129 & -0.0841 & -0.0130 & 0.0128 \\
SMB & 0.00004 & 0.00010 & 0.0059 & -0.0430 & -0.0069 & 0.0067 \\
HML & -0.00003 & -0.00020 & 0.0069 & -0.0251 & -0.0063 & 0.0061 \\
Momentum & -0.00001 & 0.00050 & 0.0104 & 0.1214 & -0.0102 & 0.0099 \\
SMB ${ }^{H X Z}$ & 0.00013 & 0.00004 & 0.0062 & 0.0057 & -0.0072 & 0.0068 \\
IA & 0.00017 & 0.00008 & 0.0042 & 0.0541 & -0.0043 & 0.0049 \\
ROE & 0.00040 & 0.00038 & 0.0044 & 0.0191 & -0.0043 & 0.0054 \\
dVVIX & 0.00127 & -0.00226 & 0.0498 & 0.0005 & -0.0481 & 0.0540 \\
dVoVIX & 0.00022 & 0.00503 & 0.0421 & 0.1784 & -0.0338 & 0.0295 \\
\hline \hline
\end{tabular}


Table 2: Summary Statistics (continued)

Panel B: VVIX Summary Statistics

\begin{tabular}{lccccc}
\hline \hline Year & Mean & Median & Std. dev. & P10 & P90 \\
\hline 2006 & 0.8024 & 0.8073 & 0.1126 & 0.6601 & 0.9467 \\
2007 & 0.8768 & 0.8618 & 0.1331 & 0.7194 & 1.0469 \\
2008 & 0.8185 & 0.7741 & 0.1560 & 0.6763 & 1.1088 \\
2009 & 0.7978 & 0.7913 & 0.0863 & 0.6954 & 0.9225 \\
2010 & 0.8836 & 0.8622 & 0.1307 & 0.7538 & 1.0346 \\
2011 & 0.9294 & 0.9146 & 0.1021 & 0.8182 & 1.0491 \\
2012 & 0.9484 & 0.9384 & 0.0838 & 0.8416 & 1.0740 \\
2013 & 0.8052 & 0.7960 & 0.0897 & 0.6967 & 0.9203 \\
2014 & 0.8301 & 0.7991 & 0.1433 & 0.6771 & 0.9990 \\
2015 & 0.9482 & 0.9041 & 0.1475 & 0.8002 & 1.1533 \\
2016 & 0.9258 & 0.8981 & 0.1021 & 0.8260 & 1.0949 \\
\hline total & 0.8696 & 0.8523 & 0.1332 & 0.7100 & 1.0450 \\
\hline \hline
\end{tabular}

Panel C: $\beta^{\mathrm{Q}}$ Summary Statistics

\begin{tabular}{lccccc}
\hline \hline Year & Mean & Median & Std. dev. & P10 & P90 \\
\hline $2006-2007$ & 0.0093 & 0.0074 & 0.0502 & -0.0425 & 0.0650 \\
$2007-2008$ & 0.0085 & 0.0072 & 0.0730 & -0.0693 & 0.0904 \\
$2008-2009$ & 0.0433 & 0.0367 & 0.1050 & -0.0619 & 0.1585 \\
$2009-2010$ & 0.0066 & 0.0053 & 0.0687 & -0.0593 & 0.0751 \\
$2010-2011$ & 0.0105 & 0.0093 & 0.0521 & -0.0443 & 0.0675 \\
$2011-2012$ & 0.0131 & 0.0118 & 0.0559 & -0.0455 & 0.0766 \\
$2012-2013$ & 0.0037 & 0.0018 & 0.0627 & -0.0617 & 0.0729 \\
$2013-2014$ & -0.0054 & -0.0040 & 0.0648 & -0.0724 & 0.0581 \\
$2014-2015$ & -0.0057 & -0.0043 & 0.0590 & -0.0631 & 0.0489 \\
$2015-2016$ & -0.0060 & -0.0073 & 0.0626 & -0.0654 & 0.0559 \\
\hline total & 0.0078 & 0.0049 & 0.0684 & -0.0589 & 0.0789 \\
\hline \hline
\end{tabular}




\section{Table 3: Predictability of the VIX and VVIX}

This table presents the results of monthly non-overlapping predictive regressions for the realized variance of the S\&P 500 and the VIX over the following month. Constant refers to the regression intercept while Slope VIX and Slope VVIX denote the regression slope coefficients on the VIX and VVIX, respectively. adj. $\mathrm{R}^{2}$ denotes the adjusted $\mathrm{R}^{2}$ of the regression. Robust Newey \& West (1987) standard errors (s.e.) using 4 lags are reported in parentheses. *, **, and *** indicate significance at $10 \%, 5 \%$, and $1 \%$, respectively.

\begin{tabular}{llllllll}
\hline \hline & \multicolumn{3}{c}{ Volatility Forecasting } & & \multicolumn{2}{c}{ Volatility-of-Volatility Forecasting } \\
\cline { 2 - 3 } Constant & -0.0190 & -0.0173 & -0.0185 & & $0.3035^{* * *}$ & 0.0215 & 0.0217 \\
(s.e.) & $(0.040)$ & $(0.076)$ & $(0.040)$ & & $(0.070)$ & $(0.046)$ & $(0.046)$ \\
Slope VIX & $0.8847^{* * *}$ & & $0.8850^{* * *}$ & & -0.0139 & & $-0.1753^{*}$ \\
(s.e.) & $(0.047)$ & & $(0.124)$ & & $(0.084)$ & & $(0.096)$ \\
Slope VVIX & & $0.2068^{* *}$ & -0.0007 & & $0.3238^{* * *}$ & $0.3649^{* * *}$ \\
(s.e.) & & $(0.094)$ & $(0.050)$ & & $(0.054)$ & $(0.059)$ \\
\hline adj. R & 0.583 & 0.053 & 0.580 & -0.008 & 0.135 & 0.148 \\
\hline \hline
\end{tabular}




\section{Table 4: Portfolios Sorted by Exposure to Aggregate Volatility-of-Volatility}

At the beginning of each month, we form quintile portfolios based on the stock's sensitivities to innovations in aggregate volatility-of-volatility $\left(\beta_{j, t}^{\mathrm{Q}}\right)$ over the following year. To obtain the sensitivities, we regress daily excess stock returns on dVVIX, controlling for MKT and dVIX as in Equation (14). Stocks with the lowest $\beta_{j, t}^{\mathrm{Q}}$ are sorted into portfolio 1 , those with the highest $\beta_{j, t}^{\mathrm{Q}}$ into portfolio 5. The column labeled 5 minus 1 refers to the hedge portfolio buying the quintile of stocks with the highest $\beta_{j, t}^{\mathrm{Q}}$ and simultaneously selling the stocks in the quintile with the lowest $\beta_{j, t}^{\mathrm{Q}}$. Each month, we set up new 12-month portfolios. The row labeled Mean return is based on monthly simple returns. CAPM alpha, 4-factor alpha, and 5-factor alpha refer to the alphas of the CAPM, the Carhart (1997) 4-factor, and the 5-factor models (including Pastor \& Stambaugh (2003) liquidity), respectively. HXZ alpha denotes the alpha relative to the Hou et al. (2015b) factor model. The segment Factor loadings denotes the value-weighted average annual factor loadings, where $\beta^{\mathrm{M}}$, $\beta^{\mathrm{V}}$, and $\beta^{\mathrm{Q}}$ refer to the factor loadings on the market factor, dVIX, and dVVIX, respectively. The segment Stock characteristics presents average (value-weighted) portfolio characteristics with Mkt. share denoting the average market share of the portfolios. The remaining variable definitions are provided in the Appendix. Robust Newey \& West (1987) p-values using 12 lags are reported in parentheses. $* * *$, and $* * *$ indicate significance at $10 \%, 5 \%$, and $1 \%$, respectively. 
Table 4: Portfolios Sorted by Exposure to Aggregate Volatility-of-Volatility (continued)

\begin{tabular}{|c|c|c|c|c|c|c|}
\hline Rank & 1 & 2 & 3 & 4 & 5 & 5 minus 1 \\
\hline $\begin{array}{l}\text { equally weighted } \\
\text { Mean return }\end{array}$ & $\begin{array}{l}0.1004 \\
(0.156)\end{array}$ & $\begin{array}{c}0.1062^{* *} \\
(0.049)\end{array}$ & $\begin{array}{c}0.0987^{*} \\
(0.069)\end{array}$ & $\begin{array}{l}0.0826 \\
(0.141)\end{array}$ & $\begin{array}{l}0.0514 \\
(0.460)\end{array}$ & $\begin{array}{c}-0.0491^{* *} \\
(0.027)\end{array}$ \\
\hline CAPM alpha & $\begin{array}{c}-0.0106 \\
(0.699)\end{array}$ & $\begin{array}{l}0.0201 \\
(0.113)\end{array}$ & $\begin{array}{l}0.0123 \\
(0.292)\end{array}$ & $\begin{array}{c}-0.0064 \\
(0.629)\end{array}$ & $\begin{array}{c}-0.0593^{* *} \\
(0.014)\end{array}$ & $\begin{array}{c}-0.0487^{* *} \\
(0.021)\end{array}$ \\
\hline 4-factor alpha & $\begin{array}{l}-0.0072 \\
(0.504)\end{array}$ & $\begin{array}{c}0.0189^{* * *} \\
(0.000)\end{array}$ & $\begin{array}{c}0.0147^{* * *} \\
(0.000)\end{array}$ & $\begin{array}{c}-0.0052^{*} \\
(0.081)\end{array}$ & $\begin{array}{c}-0.0563^{* * *} \\
(0.000)\end{array}$ & $\begin{array}{c}-0.0491^{* * *} \\
(0.004)\end{array}$ \\
\hline 5-factor alpha & $\begin{array}{l}-0.0023 \\
(0.840)\end{array}$ & $\begin{array}{c}0.0194^{* * *} \\
(0.000)\end{array}$ & $\begin{array}{c}0.0137^{* * *} \\
(0.000)\end{array}$ & $\begin{array}{c}-0.0049 \\
(0.120)\end{array}$ & $\begin{array}{c}-0.0485^{* * *} \\
(0.000)\end{array}$ & $\begin{array}{c}-0.0462^{* *} \\
(0.022)\end{array}$ \\
\hline HXZ alpha & $\begin{array}{l}0.0103 \\
(0.457)\end{array}$ & $\begin{array}{c}0.0264^{* * *} \\
(0.000)\end{array}$ & $\begin{array}{c}0.0153^{* * *} \\
(0.004)\end{array}$ & $\begin{array}{c}-0.0074 \\
(0.305)\end{array}$ & $\begin{array}{c}-0.0532^{* * *} \\
(0.000)\end{array}$ & $\begin{array}{c}-0.0635^{* *} \\
(0.015)\end{array}$ \\
\hline $\begin{array}{l}\text { value-weighted } \\
\text { Mean return }\end{array}$ & $\begin{array}{l}0.0967 \\
(0.111)\end{array}$ & $\begin{array}{c}0.0951^{* *} \\
(0.047)\end{array}$ & $\begin{array}{c}0.0914^{* *} \\
(0.044)\end{array}$ & $\begin{array}{l}0.0652 \\
(0.198)\end{array}$ & $\begin{array}{l}0.0433 \\
(0.518)\end{array}$ & $\begin{array}{c}-0.0533^{*} \\
(0.089)\end{array}$ \\
\hline CAPM alpha & $\begin{array}{l}-0.0003 \\
(0.985)\end{array}$ & $\begin{array}{c}0.0193^{* * *} \\
(0.000)\end{array}$ & $\begin{array}{c}0.0185^{* * *} \\
(0.000)\end{array}$ & $\begin{array}{r}-0.0140 \\
(0.121)\end{array}$ & $\begin{array}{c}-0.0629^{* * *} \\
(0.007)\end{array}$ & $\begin{array}{c}-0.0626^{*} \\
(0.056)\end{array}$ \\
\hline 4-factor alpha & $\begin{array}{c}-0.0039 \\
(0.755)\end{array}$ & $\begin{array}{c}0.0161^{* * * *} \\
(0.001)\end{array}$ & $\begin{array}{c}0.0195^{* * *} \\
(0.000)\end{array}$ & $\begin{array}{l}-0.0091 \\
(0.196)\end{array}$ & $\begin{array}{c}-0.0507^{* * * *} \\
(0.004)\end{array}$ & $\begin{array}{c}-0.0468^{*} \\
(0.075)\end{array}$ \\
\hline 5-factor alpha & $\begin{array}{l}0.0063 \\
(0.553)\end{array}$ & $\begin{array}{c}0.0194^{* * *} \\
(0.000)\end{array}$ & $\begin{array}{c}0.0144^{* * *} \\
(0.000)\end{array}$ & $\begin{array}{c}-0.0126^{*} \\
(0.058)\end{array}$ & $\begin{array}{c}-0.0508^{* *} \\
(0.015)\end{array}$ & $\begin{array}{c}-0.0572^{*} \\
(0.057)\end{array}$ \\
\hline HXZ alpha & $\begin{array}{l}0.0198 \\
(0.199)\end{array}$ & $\begin{array}{c}0.0204^{* * *} \\
(0.000)\end{array}$ & $\begin{array}{c}0.0173^{* * *} \\
(0.000)\end{array}$ & $\begin{array}{l}-0.0148 \\
(0.264)\end{array}$ & $\begin{array}{c}-0.0657^{* * * *} \\
(0.009)\end{array}$ & $\begin{array}{c}-0.0855^{* *} \\
(0.029)\end{array}$ \\
\hline $\begin{array}{l}\text { Factor loadings } \\
\beta^{\mathrm{M}}\end{array}$ & $\begin{array}{c}1.0708^{* * * *} \\
(0.000)\end{array}$ & $\begin{array}{c}0.9253^{* * *} \\
(0.000)\end{array}$ & $\begin{array}{c}0.9729 * * * \\
(0.000)\end{array}$ & $\begin{array}{c}1.0989 * * * \\
(0.000)\end{array}$ & $\begin{array}{c}1.3848^{* * *} \\
(0.000)\end{array}$ & $\begin{array}{c}0.3140 * * * \\
(0.000)\end{array}$ \\
\hline$\beta^{\mathrm{V}}$ & $\begin{array}{c}0.1441^{* * *} \\
(0.000)\end{array}$ & $\begin{array}{c}0.0395^{* * * *} \\
(0.000)\end{array}$ & $\begin{array}{r}-0.0041 \\
(0.150)\end{array}$ & $\begin{array}{c}-0.0401^{* * *} \\
(0.000)\end{array}$ & $\begin{array}{c}-0.0907^{* * *} \\
(0.000)\end{array}$ & $\begin{array}{c}-0.2349^{* * * *} \\
(0.000)\end{array}$ \\
\hline$\beta^{\mathrm{Q}}$ & $\begin{array}{c}-0.0599 * * * \\
(0.000)\end{array}$ & $\begin{array}{c}-0.0177^{* * * *} \\
(0.000)\end{array}$ & $\begin{array}{c}0.0062^{*} \\
(0.057)\end{array}$ & $\begin{array}{c}0.0313^{* * *} \\
(0.000)\end{array}$ & $\begin{array}{c}0.0777^{* * *} \\
(0.000)\end{array}$ & $\begin{array}{c}0.1376^{* * *} \\
(0.000)\end{array}$ \\
\hline $\begin{array}{l}\text { Return characteristics } \\
\text { Std. deviation }\end{array}$ & 0.0601 & 0.0474 & 0.0450 & 0.0504 & 0.0668 & 0.0311 \\
\hline Skewness & -0.1632 & -0.4981 & -0.8644 & -0.8132 & -0.0727 & 0.0175 \\
\hline Kurtosis & 4.0501 & 3.6484 & 3.9630 & 3.6487 & 3.8287 & 2.3774 \\
\hline Mkt. share & 0.2042 & 0.2467 & 0.2209 & 0.2034 & 0.1248 & -0.0794 \\
\hline $\log ($ Size $)$ & 16.863 & 17.444 & 17.330 & 17.087 & 16.314 & -0.5490 \\
\hline Book-to-market & 0.5416 & 0.4850 & 0.4805 & 0.5196 & 0.6716 & 0.1299 \\
\hline Bid-ask spread & 0.0008 & 0.0006 & 0.0006 & 0.0006 & 0.0009 & 0.0002 \\
\hline Age & 33.491 & 41.099 & 38.442 & 35.074 & 28.564 & -4.9267 \\
\hline Leverage & 0.5567 & 0.5549 & 0.5622 & 0.5861 & 0.6015 & 0.0448 \\
\hline
\end{tabular}




\section{Table 5: Dissecting the Effects of Aggregate Risk and Aggregate Volatility-of-Volatility}

This table reports Hou et al. (2015b) factor alphas for double-sorted portfolios. We obtain the factor sensitivities in a joint multivariate estimation. At the beginning of each month, we independently sort stocks into quintiles based on their sensitivity to aggregate volatility (Panels A and B) and the market variance risk premium (Panels $\mathrm{C}$ and D) as well as their volatility-of-volatility-sensitivities $\left(\beta_{j, t}^{\mathrm{Q}}\right)$ using NYSE breakpoints. We report the alphas of all 25 portfolios as well as the respective long minus short (5 minus 1) portfolios. Each month, we set up new 12-month portfolios. Robust Newey \& West (1987) p-values using 12 lags are reported in parentheses. *, **, and *** indicate significance at $10 \%, 5 \%$, and $1 \%$, respectively.

Panel A: Aggregate Volatility - Equally Weighted

\begin{tabular}{|c|c|c|c|c|c|c|c|}
\hline & & \multicolumn{5}{|c|}{ dVIX } & \multirow[b]{2}{*}{5 minus 1} \\
\hline & & 1 & 2 & 3 & 4 & 5 & \\
\hline \multirow{9}{*}{ dVVIX } & 1 & $\begin{array}{c}0.0741^{*} \\
(0.053)\end{array}$ & $\begin{array}{c}0.0716^{* * *} \\
(0.000)\end{array}$ & $\begin{array}{c}0.0578^{* * *} \\
(0.000)\end{array}$ & $\begin{array}{c}0.0277^{* *} \\
(0.036)\end{array}$ & $\begin{array}{c}-0.0497^{* * *} \\
(0.000)\end{array}$ & $\begin{array}{c}-0.1238^{* * *} \\
(0.000)\end{array}$ \\
\hline & 2 & $\begin{array}{c}0.0777^{* * *} \\
(0.000)\end{array}$ & $\begin{array}{c}0.0684^{* * *} \\
(0.000)\end{array}$ & $\begin{array}{c}0.0591 * * * \\
(0.000)\end{array}$ & $\begin{array}{l}0.0068 \\
(0.268)\end{array}$ & $\begin{array}{c}-0.0566^{* * * *} \\
(0.000)\end{array}$ & $\begin{array}{c}-0.1343^{* * *} \\
(0.000)\end{array}$ \\
\hline & 3 & $\begin{array}{c}0.0653^{* * *} \\
(0.000)\end{array}$ & $\begin{array}{c}0.0443^{* * *} \\
(0.000)\end{array}$ & $\begin{array}{c}0.0288^{* * *} \\
(0.000)\end{array}$ & $\begin{array}{l}0.0041 \\
(0.618)\end{array}$ & $\begin{array}{c}-0.0699 * * * \\
(0.000)\end{array}$ & $\begin{array}{c}-0.1352^{* * *} \\
(0.000)\end{array}$ \\
\hline & 4 & $\begin{array}{c}0.0454^{* * *} \\
(0.000)\end{array}$ & $\begin{array}{c}0.0327^{* * *} \\
(0.000)\end{array}$ & $\begin{array}{c}0.0111 \\
(0.165)\end{array}$ & $\begin{array}{c}-0.0307^{* *} \\
(0.016)\end{array}$ & $\begin{array}{c}-0.0920 * * * \\
(0.000)\end{array}$ & $\begin{array}{c}-0.1374^{* * *} \\
(0.000)\end{array}$ \\
\hline & 5 & $\begin{array}{r}-0.0075 \\
(0.510)\end{array}$ & $\begin{array}{c}-0.0339 * * * \\
(0.001)\end{array}$ & $\begin{array}{c}-0.0523^{* * *} \\
(0.000)\end{array}$ & $\begin{array}{c}-0.0810^{* * *} \\
(0.001)\end{array}$ & $\begin{array}{c}-0.1277^{* * *} \\
(0.001)\end{array}$ & $\begin{array}{c}-0.1202^{* * *} \\
(0.004)\end{array}$ \\
\hline & 5 minus 1 & $\begin{array}{c}-0.0817^{*} \\
(0.058)\end{array}$ & $\begin{array}{c}-0.1055^{* * *} \\
(0.000)\end{array}$ & $\begin{array}{c}-0.1101^{* * *} \\
(0.000)\end{array}$ & $\begin{array}{c}-0.1086^{* * *} \\
(0.001)\end{array}$ & $\begin{array}{c}-0.0781^{*} \\
(0.060)\end{array}$ & \\
\hline & \multicolumn{6}{|c|}{ Panel B: Aggregate Volatility - Value-Weighted } & \\
\hline & & & & dVIX & & & \\
\hline & & 1 & 2 & 3 & 4 & 5 & 5 minus 1 \\
\hline \multirow{6}{*}{ dVVIX } & 1 & $\begin{array}{c}0.1007^{* * *} \\
(0.001)\end{array}$ & $\begin{array}{c}0.0664^{* * *} \\
(0.000)\end{array}$ & $\begin{array}{c}0.0394^{* * *} \\
(0.006)\end{array}$ & $\begin{array}{l}0.0135 \\
(0.335)\end{array}$ & $\begin{array}{c}-0.0803^{* * *} \\
(0.000)\end{array}$ & $\begin{array}{c}-0.1810^{* * *} \\
(0.000)\end{array}$ \\
\hline & 2 & $\begin{array}{c}0.0794^{* * *} \\
(0.000)\end{array}$ & $\begin{array}{c}0.0574^{* * *} \\
(0.000)\end{array}$ & $\begin{array}{c}0.0278^{* * *} \\
(0.000)\end{array}$ & $\begin{array}{c}-0.0250^{* * *} \\
(0.000)\end{array}$ & $\begin{array}{c}-0.0547^{* * *} \\
(0.001)\end{array}$ & $\begin{array}{c}-0.1341^{* * *} \\
(0.000)\end{array}$ \\
\hline & 3 & $\begin{array}{c}0.0594^{* * *} \\
(0.000)\end{array}$ & $\begin{array}{c}0.0315^{* * *} \\
(0.000)\end{array}$ & $\begin{array}{c}0.0241^{* * *} \\
(0.000)\end{array}$ & $\begin{array}{r}-0.0118 \\
(0.192)\end{array}$ & $\begin{array}{c}-0.0978^{* * *} \\
(0.000)\end{array}$ & $\begin{array}{c}-0.1573^{* * *} \\
(0.000)\end{array}$ \\
\hline & 4 & $\begin{array}{c}0.0360^{* * *} \\
(0.007)\end{array}$ & $\begin{array}{c}0.0032 \\
(0.737)\end{array}$ & $\begin{array}{r}-0.0017 \\
(0.912)\end{array}$ & $\begin{array}{c}-0.0507^{* *} \\
(0.016)\end{array}$ & $\begin{array}{c}-0.1186^{* * *} \\
(0.000)\end{array}$ & $\begin{array}{c}-0.1546^{* * *} \\
(0.000)\end{array}$ \\
\hline & 5 & $\begin{array}{r}-0.0217 \\
(0.128)\end{array}$ & $\begin{array}{c}-0.0305 \\
(0.220)\end{array}$ & $\begin{array}{c}-0.0769^{* * *} \\
(0.000)\end{array}$ & $\begin{array}{c}-0.0915^{* * *} \\
(0.005)\end{array}$ & $\begin{array}{c}-0.1444^{* * *} \\
(0.000)\end{array}$ & $\begin{array}{c}-0.1227^{* * *} \\
(0.002)\end{array}$ \\
\hline & 5 minus 1 & $\begin{array}{c}-0.1224^{* * *} \\
(0.003)\end{array}$ & $\begin{array}{c}-0.0969^{* *} \\
(0.018)\end{array}$ & $\begin{array}{c}-0.1163^{* * *} \\
(0.000)\end{array}$ & $\begin{array}{c}-0.1051^{* *} \\
(0.012)\end{array}$ & $\begin{array}{l}-0.0641 \\
(0.145)\end{array}$ & \\
\hline
\end{tabular}


Table 5: Dissecting the Effects of Aggregate Risk and Aggregate Volatility-of-Volatility (continued)

Panel C: Market Variance Risk Premium - Equally Weighted

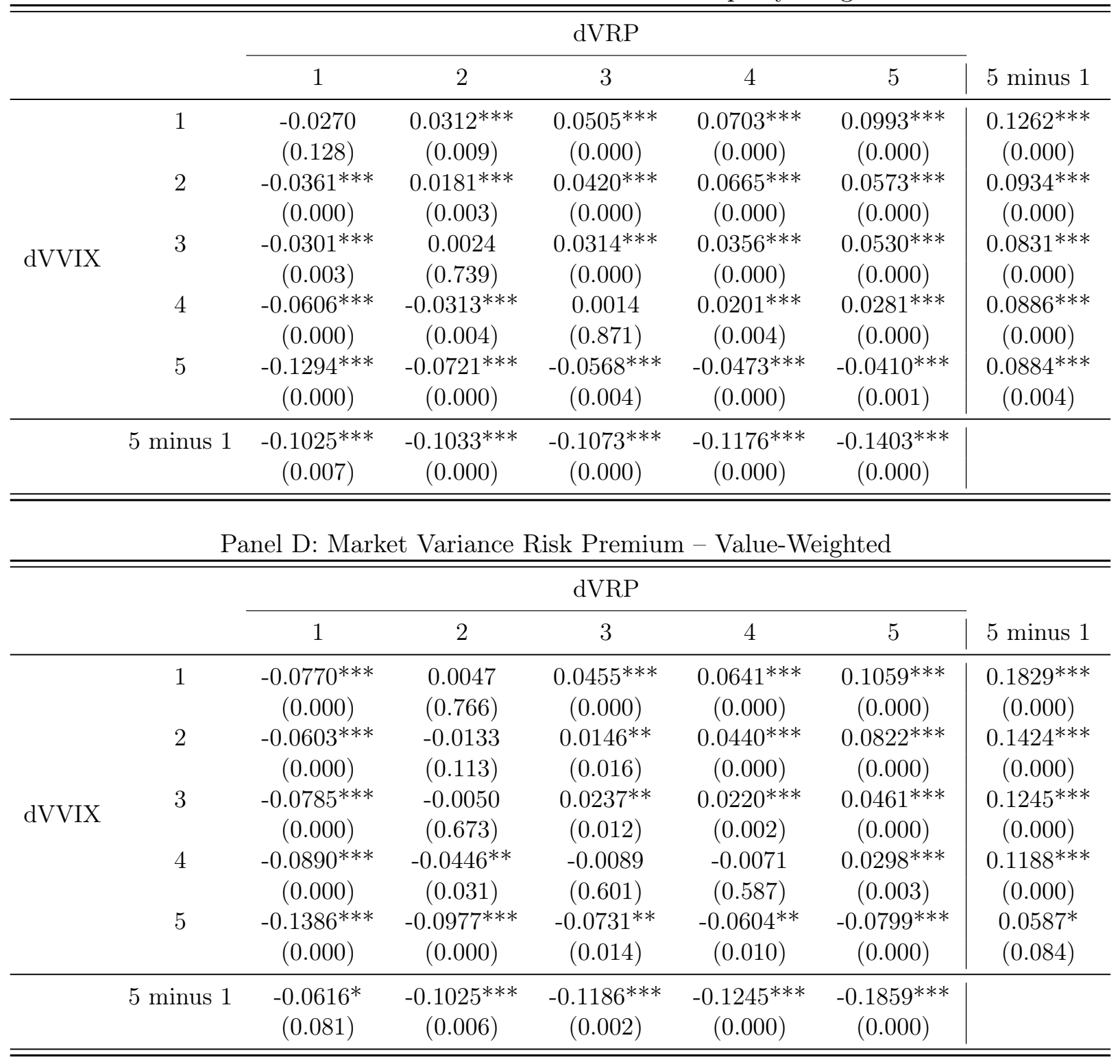




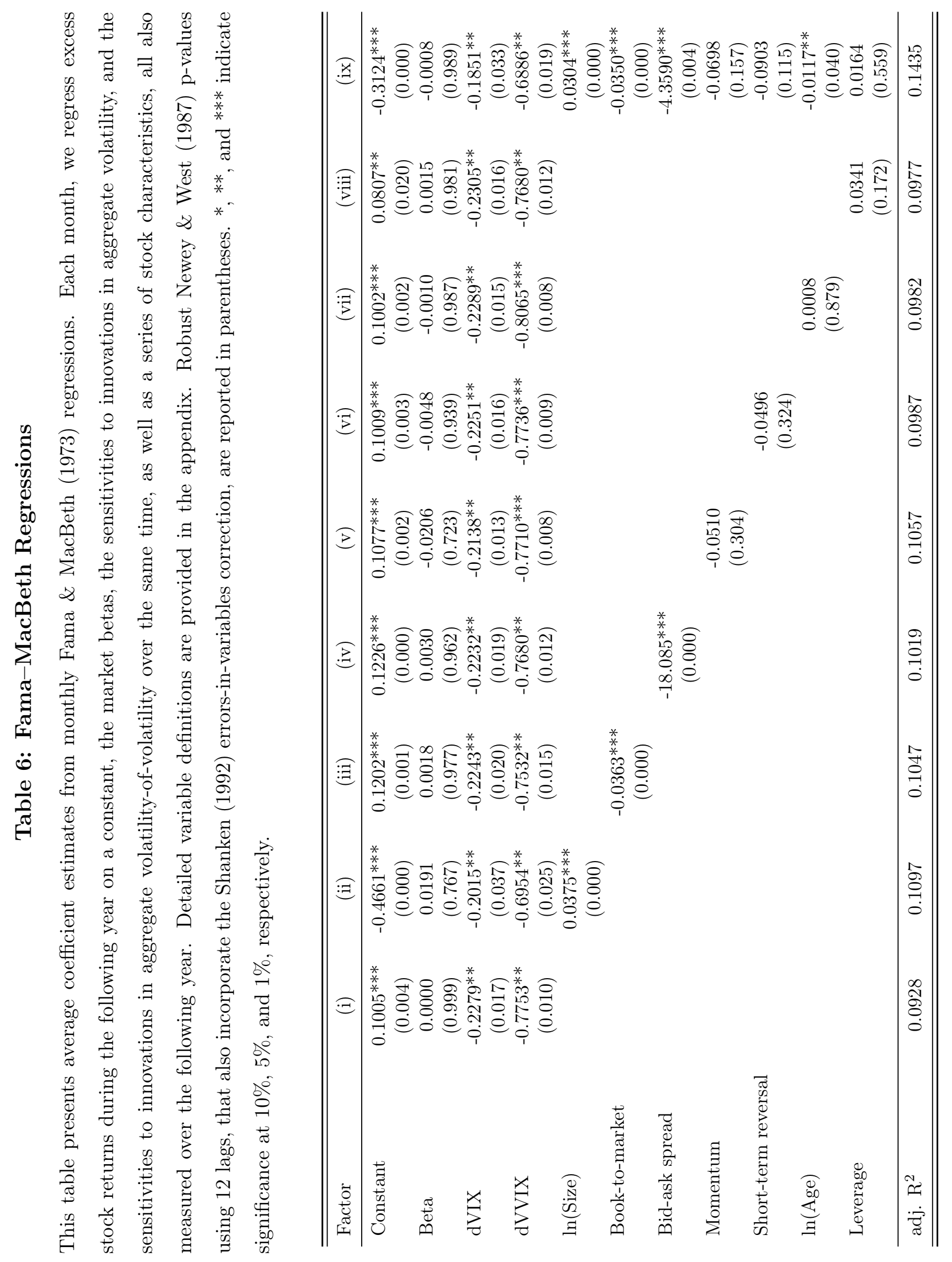




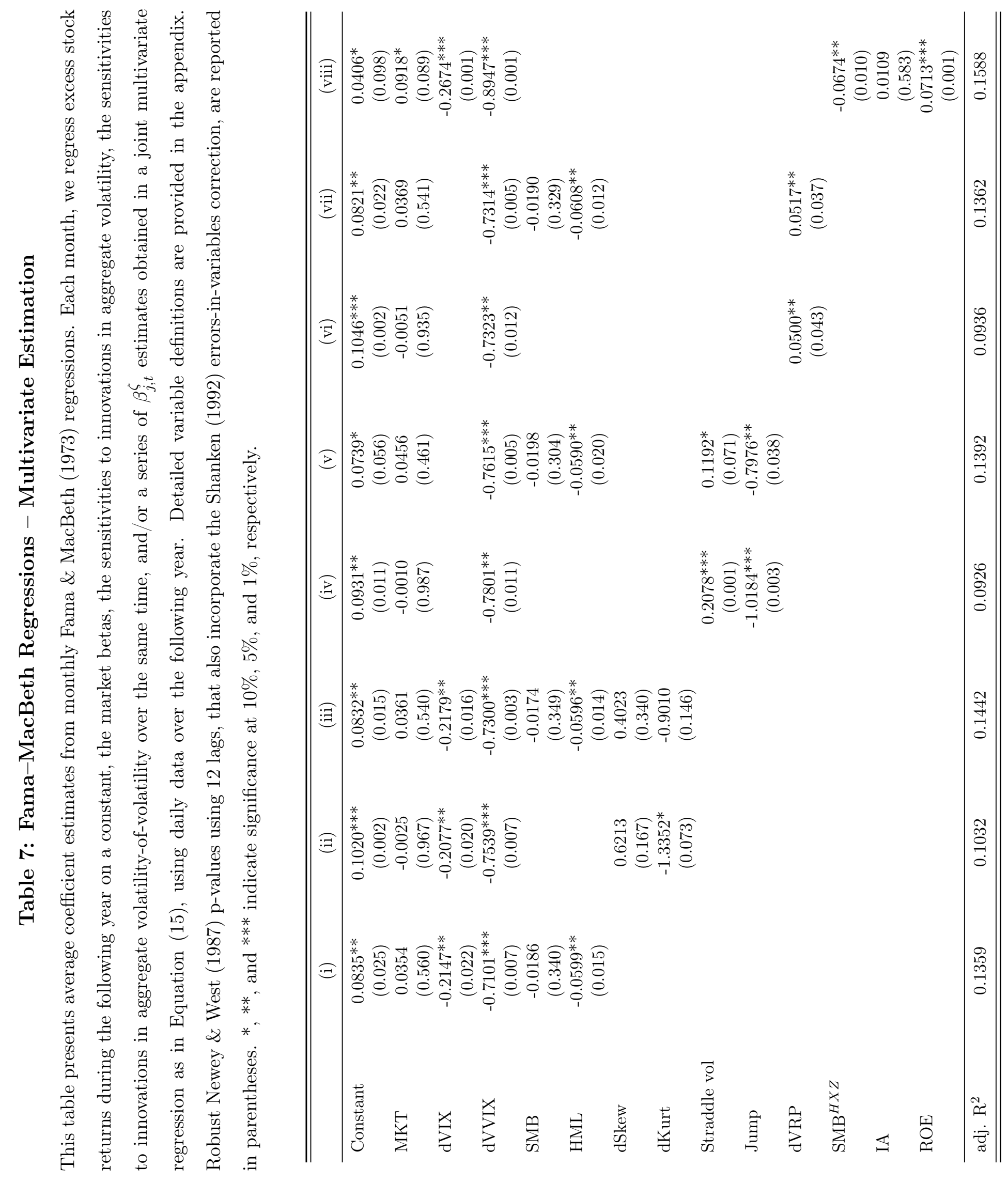




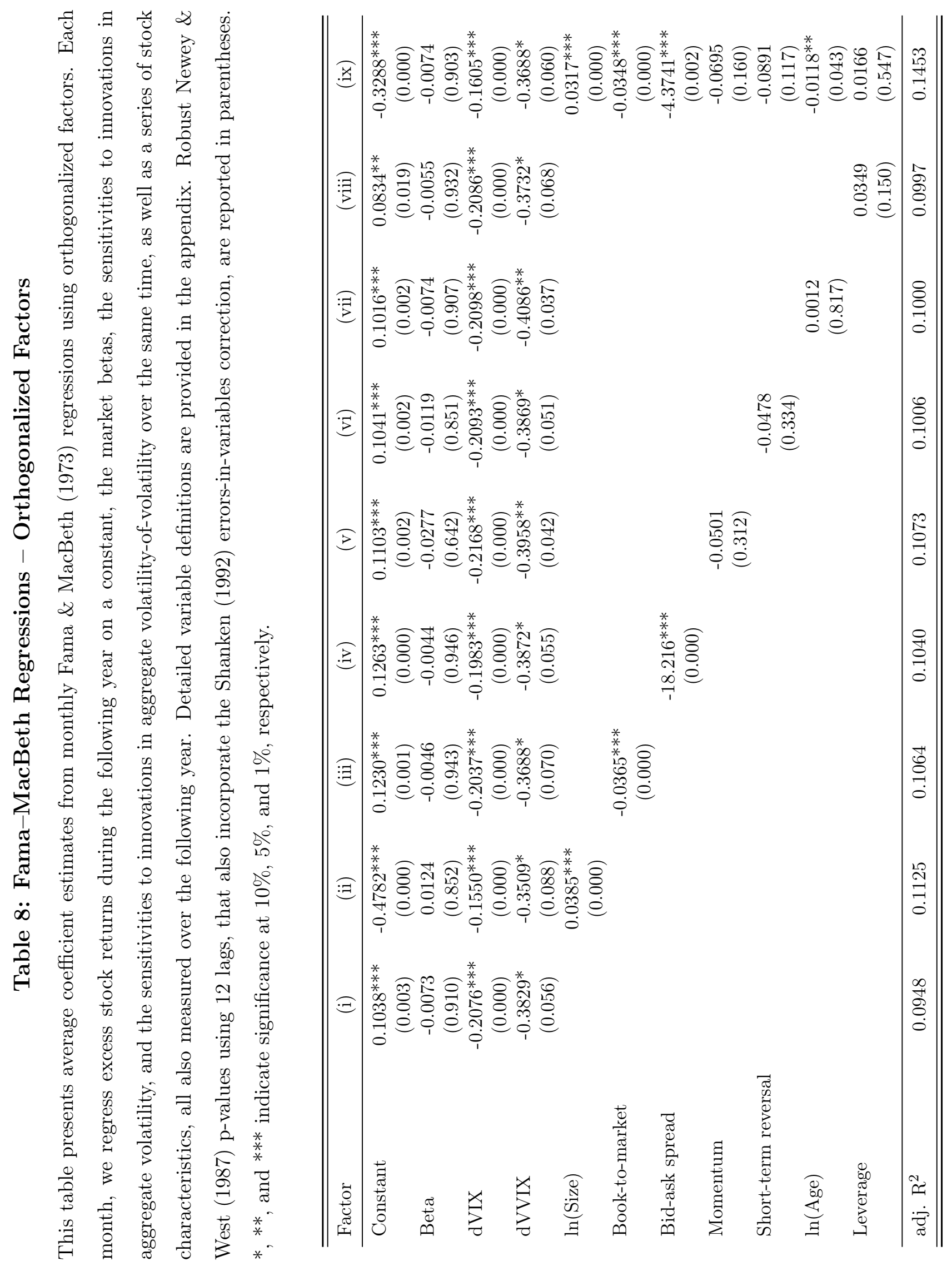




\section{Table 9: Pre-Formation Factor Loadings}

At the beginning of each month, we form quintile portfolios based on the stock's sensitivities to aggregate volatility-of-volatility $\left(\beta_{j, t}^{\mathrm{Q}}\right)$ over the past year. To obtain the sensitivities, we regress daily excess stock returns on dVVIX, controlling for MKT and dVIX as in Equation (14). Stocks with the lowest $\beta_{j, t}^{\mathrm{Q}}$ are sorted into portfolio 1 , those with the highest $\beta_{j, t}^{\mathrm{Q}}$ into portfolio 5 . The column labeled 5 minus 1 refers to the hedge portfolio buying the quintile of stocks with the highest $\beta_{j, t}^{\mathrm{Q}}$ and simultaneously selling the stocks in the quintile with the lowest $\beta_{j, t}^{\mathrm{Q}}$. Each month, we set up new 12-month portfolios. We report Hou et al. (2015b) factor alphas for portfolios based on returns over the following year. Robust Newey \& West (1987) p-values using 12 lags are reported in parentheses. ${ }^{*}, * *$, and $* * *$ indicate significance at $10 \%, 5 \%$, and $1 \%$, respectively. The columns ex post $\beta^{\mathrm{Q}}$ report the average annual ex post sensitivities to aggregate volatility-of-volatility of the portfolios.

\begin{tabular}{l|ccccc|c}
\hline \hline Rank & 1 & 2 & 3 & 4 & 5 & 5 minus 1 \\
\hline equally weighted & & & & & & \\
Mean return & $\begin{array}{l}0.0891 \\
(0.123)\end{array}$ & $\begin{array}{c}0.0918^{*} \\
(0.071)\end{array}$ & $\begin{array}{c}0.0871 \\
(0.113)\end{array}$ & $\begin{array}{c}0.0804 \\
(0.174)\end{array}$ & $\begin{array}{c}0.0997 \\
(0.147)\end{array}$ & $\begin{array}{c}0.0106 \\
(0.682)\end{array}$ \\
\hline HXZ alpha & $\begin{array}{l}0.0047 \\
(0.742)\end{array}$ & $\begin{array}{c}0.0208^{* * *} \\
(0.003)\end{array}$ & $\begin{array}{c}0.0210^{* * *} \\
(0.000)\end{array}$ & $\begin{array}{c}0.0038 \\
(0.460)\end{array}$ & $\begin{array}{c}0.0106 \\
(0.341)\end{array}$ & 0.0059 \\
& 0.0082 & 0.0055 & 0.0063 & 0.0084 & 0.0101 & 0.0019 \\
\hline ex post $\beta^{\mathrm{V}}$ & & & & & & \\
\hline \hline value-weighted & 0.0807 & 0.0929 & 0.1019 & 0.0979 & 0.0971 & 0.0164 \\
Mean return & $(0.242)$ & $(0.137)$ & $(0.105)$ & $(0.125)$ & $(0.171)$ & $(0.253)$ \\
\hline HXZ alpha & -0.0084 & 0.0071 & $0.0132^{* *}$ & $0.0091^{*}$ & -0.0009 & 0.0075 \\
& $(0.289)$ & $(0.252)$ & $(0.016)$ & $(0.098)$ & $(0.909)$ & $(0.580)$ \\
\hline ex post $\beta^{\mathrm{V}}$ & 0.0068 & 0.0025 & 0.0005 & -0.0010 & 0.0011 & -0.0057 \\
\hline \hline
\end{tabular}




\section{Table 10: Determinants of Relative Sensitivities to Aggregate Volatility-of-Volatility}

This table presents average coefficient estimates from monthly Fama \& MacBeth (1973) regressions. Each month, we regress the sensitivity to innovations in aggregate volatility-of-volatility during the following year on a constant and a series of stock characteristics, all measured over the past year. Detailed variable definitions are provided in the appendix. Robust Newey \& West (1987) p-values using 12 lags, that also incorporate the Shanken (1992) errors-in-variables correction, are reported in parentheses. ${ }^{*}, * *$, and $* * *$ indicate significance at $10 \%, 5 \%$, and $1 \%$, respectively.

\begin{tabular}{|c|c|c|c|c|c|c|c|}
\hline Factor & (i) & (ii) & (iii) & (iv) & (v) & (vi) & (vii) \\
\hline Constant & $\begin{array}{c}-0.0068^{* *} \\
(0.023)\end{array}$ & $\begin{array}{c}0.0136 \\
(0.509)\end{array}$ & $\begin{array}{c}-0.0062^{*} \\
(0.068)\end{array}$ & $\begin{array}{c}-0.0066^{* *} \\
(0.026)\end{array}$ & $\begin{array}{c}-0.0063^{* *} \\
(0.044)\end{array}$ & $\begin{array}{c}-0.0072^{* *} \\
(0.038)\end{array}$ & $\begin{array}{c}0.0288 \\
(0.287)\end{array}$ \\
\hline Beta & $\begin{array}{c}0.0115^{* * *} \\
(0.000)\end{array}$ & $\begin{array}{c}0.0107^{* * *} \\
(0.000)\end{array}$ & $\begin{array}{c}0.0115^{* * *} \\
(0.000)\end{array}$ & $\begin{array}{c}0.0115^{* * *} \\
(0.000)\end{array}$ & $\begin{array}{c}0.0157^{* *} \\
(0.019)\end{array}$ & $\begin{array}{c}0.0091^{* * *} \\
(0.000)\end{array}$ & $\begin{array}{c}0.0253^{* * *} \\
(0.001)\end{array}$ \\
\hline dVIX & $\begin{array}{c}-0.0010 \\
(0.779)\end{array}$ & $\begin{array}{c}-0.0002 \\
(0.943)\end{array}$ & $\begin{array}{c}-0.0009 \\
(0.840)\end{array}$ & $\begin{array}{l}0.0012 \\
(0.762)\end{array}$ & $\begin{array}{c}-0.0059 \\
(0.465)\end{array}$ & $\begin{array}{l}0.0046 \\
(0.265)\end{array}$ & $\begin{array}{c}-0.0164 \\
(0.119)\end{array}$ \\
\hline dVVIX & $\begin{array}{l}0.0100 \\
(0.675)\end{array}$ & $\begin{array}{l}0.0074 \\
(0.744)\end{array}$ & $\begin{array}{c}0.0121 \\
(0.641)\end{array}$ & $\begin{array}{l}0.0142 \\
(0.507)\end{array}$ & $\begin{array}{l}0.0064 \\
(0.758)\end{array}$ & $\begin{array}{l}0.0207 \\
(0.380)\end{array}$ & $\begin{array}{c}-0.0078 \\
(0.736)\end{array}$ \\
\hline $\ln ($ Size $)$ & & $\begin{array}{c}-0.0014 \\
(0.263)\end{array}$ & & & & & $\begin{array}{l}-0.0021 \\
(0.180)\end{array}$ \\
\hline Book-to-market & & $\begin{array}{l}0.0000 \\
(0.997)\end{array}$ & & & & & $\begin{array}{c}-0.0009 \\
(0.408)\end{array}$ \\
\hline Bid-ask spread & & & $\begin{array}{r}-0.0523 \\
(0.859)\end{array}$ & & & & $\begin{array}{c}-0.3474^{*} \\
(0.078)\end{array}$ \\
\hline Momentum & & & $\begin{array}{c}-0.0054^{* * *} \\
(0.001)\end{array}$ & & & & $\begin{array}{c}-0.0064^{* * *} \\
(0.000)\end{array}$ \\
\hline Short-term reversal & & & $\begin{array}{r}-0.0030 \\
(0.371)\end{array}$ & & & & $\begin{array}{c}-0.0075^{* *} \\
(0.036)\end{array}$ \\
\hline Idio. volatility & & & & $\begin{array}{r}-0.0097 \\
(0.908)\end{array}$ & & & $\begin{array}{c}-0.4570^{*} \\
(0.090)\end{array}$ \\
\hline Co-Skewness & & & & $\begin{array}{l}0.0000 \\
(0.730)\end{array}$ & & & $\begin{array}{r}-0.0001 \\
(0.569)\end{array}$ \\
\hline Co-Kurtosis & & & & $\begin{array}{l}0.0000 \\
(0.671)\end{array}$ & & & $\begin{array}{l}0.0000 \\
(0.419)\end{array}$ \\
\hline Downside beta & & & & & $\begin{array}{c}-0.0054 \\
(0.388)\end{array}$ & & $\begin{array}{c}-0.0170^{* *} \\
(0.028)\end{array}$ \\
\hline MAX & & & & & $\begin{array}{l}0.0012 \\
(0.952)\end{array}$ & & $\begin{array}{l}0.0255 \\
(0.665)\end{array}$ \\
\hline Volatility & & & & & & $\begin{array}{l}0.1484 \\
(0.283)\end{array}$ & $\begin{array}{l}0.2827 \\
(0.126)\end{array}$ \\
\hline Skewness & & & & & & $\begin{array}{l}0.0005 \\
(0.564)\end{array}$ & $\begin{array}{l}-0.0002 \\
(0.763)\end{array}$ \\
\hline Kurtosis & & & & & & $\begin{array}{c}-0.0001 * \\
(0.094)\end{array}$ & $\begin{array}{r}-0.0001 \\
(0.149)\end{array}$ \\
\hline $\operatorname{adj} . R^{2}$ & 0.0179 & 0.0285 & 0.0265 & 0.0250 & 0.0228 & 0.0459 & 0.0830 \\
\hline
\end{tabular}




\section{Table 11: Delta-Hedged Option Returns}

This table presents the delta-hedged option returns of VIX-options. We use options with 30 days to maturity and hold these until expiration. The positions are dynamically delta-hedged using the Black \& Scholes (1973) delta. We separate the options into puts and calls as well as different moneyness bins, where moneyness is defined as the strike price $K$ over the futures price $F_{t}$ at initiation. Mean denotes the average return, computed as the strategy's payoff over the price of the corresponding VIX-future at initiation. T-stat denotes the t-statistic using robust Newey \& West (1987) standard errors with 4 lags. Std, SR, Skew, and Kurt denote the standard deviation of returns, its Sharpe ratio, skewness, and kurtosis, respectively. Additionally, Median and the 5\% and $95 \%$ quantiles, $\mathrm{q}^{0.05}$ and $\mathrm{q}^{0.95}$, present further details on the distribution of returns. *, **, and *** indicate significance at $10 \%, 5 \%$, and $1 \%$, respectively.

\begin{tabular}{ccccccccccc}
\hline \hline & Moneyness $\left(\frac{K}{F_{t}}\right)$ & Mean & T-stat & Std. & SR & Skew & Kurt & Median & $\mathrm{q}^{0.05}$ & $\mathrm{q}^{0.95}$ \\
\hline \multirow{6}{*}{ Calls } & {$[0.7 ; 0.8]$} & -0.0008 & -0.67 & 0.013 & -0.06 & 0.74 & 6.60 & -0.0004 & -0.0199 & 0.0225 \\
& {$[0.8 ; 0.9]$} & -0.0020 & -1.26 & 0.021 & -0.09 & 1.15 & 7.93 & -0.0021 & -0.0332 & 0.0325 \\
& {$[0.9 ; 1.0]$} & -0.0015 & -0.59 & 0.030 & -0.05 & 1.68 & 8.76 & -0.0087 & -0.0376 & 0.0507 \\
& {$[1.0 ; 1.1]$} & -0.0039 & -1.28 & 0.036 & -0.11 & 1.45 & 5.39 & -0.0119 & -0.0466 & 0.0783 \\
& {$[1.1 ; 1.2]$} & $-0.0061^{* *}$ & -2.50 & 0.031 & -0.20 & 1.35 & 5.81 & -0.0119 & -0.0451 & 0.0583 \\
& {$[1.2 ; 1.3]$} & $-0.0072^{* *}$ & -2.59 & 0.029 & -0.24 & 1.59 & 8.00 & -0.0104 & -0.0421 & 0.0615 \\
\hline \multirow{4}{*}{ Puts } & {$[0.7 ; 0.8]$} & $-0.0027^{* *}$ & -2.20 & 0.013 & -0.20 & 0.79 & 7.52 & -0.0030 & -0.0220 & 0.0134 \\
& {$[0.8 ; 0.9]$} & $-0.0029^{* *}$ & -2.03 & 0.020 & -0.14 & 0.99 & 7.31 & -0.0034 & -0.0346 & 0.0312 \\
& {$[0.9 ; 1.0]$} & -0.0021 & -0.92 & 0.029 & -0.07 & 1.68 & 9.13 & -0.0081 & -0.0388 & 0.0472 \\
& {$[1.0 ; 1.1]$} & $-0.0051^{*}$ & -1.76 & 0.035 & -0.14 & 1.43 & 5.38 & -0.0128 & -0.0475 & 0.0778 \\
& {$[1.1 ; 1.2]$} & $-0.0069^{* * *}$ & -2.78 & 0.031 & -0.22 & 1.12 & 5.36 & -0.0121 & -0.0468 & 0.0569 \\
& {$[1.2 ; 1.3]$} & $-0.0069^{* *}$ & -2.58 & 0.029 & -0.24 & 1.47 & 8.96 & -0.0107 & -0.0415 & 0.0523 \\
\hline \hline
\end{tabular}




\title{
How Aggregate Volatility-of-Volatility Affects Stock Returns
}

\author{
Online Appendix
}

JEL classification: G12, G11

Keywords: Aggregate economic uncertainty, stock market volatility-of-volatility, VVIX 


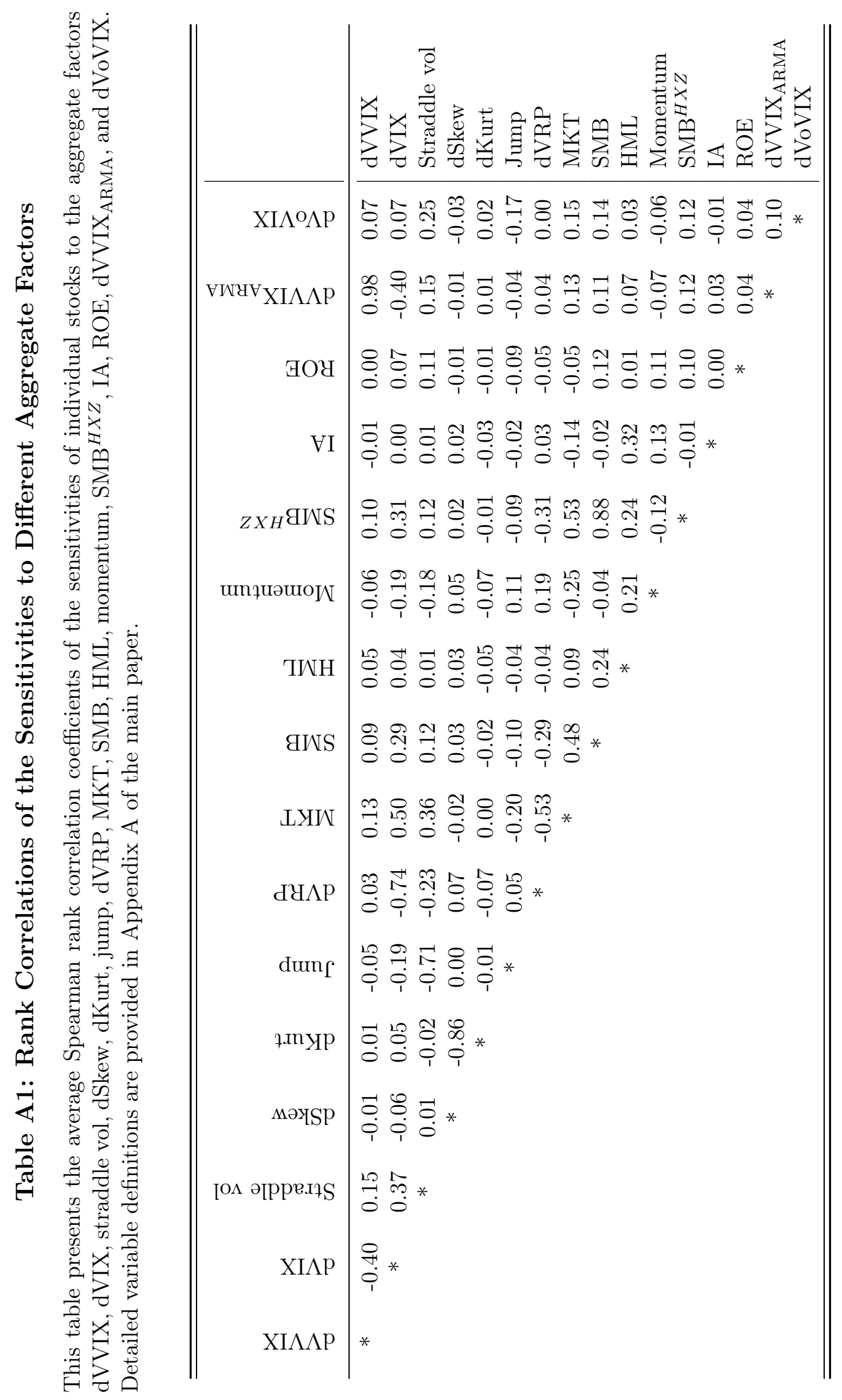




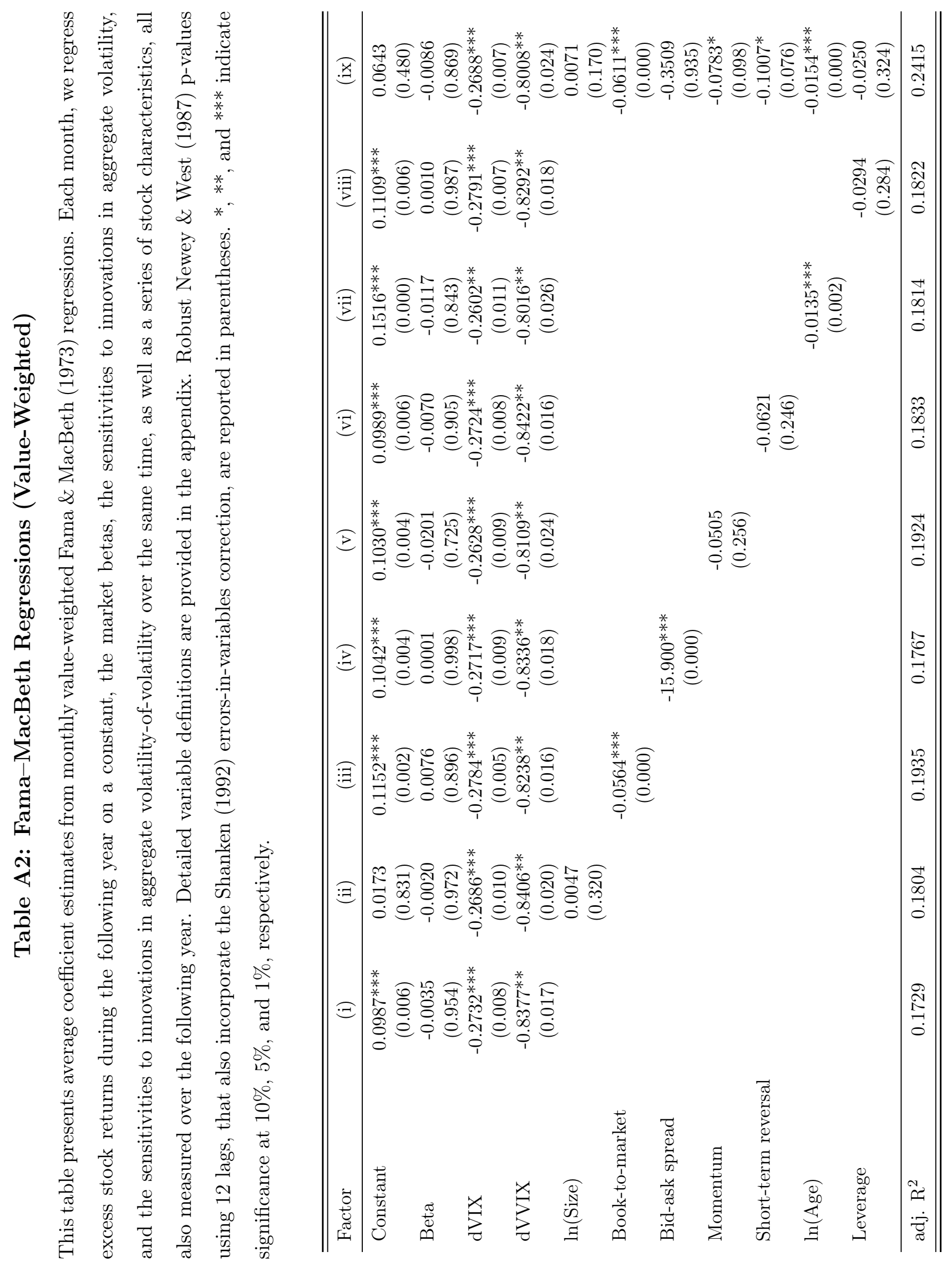




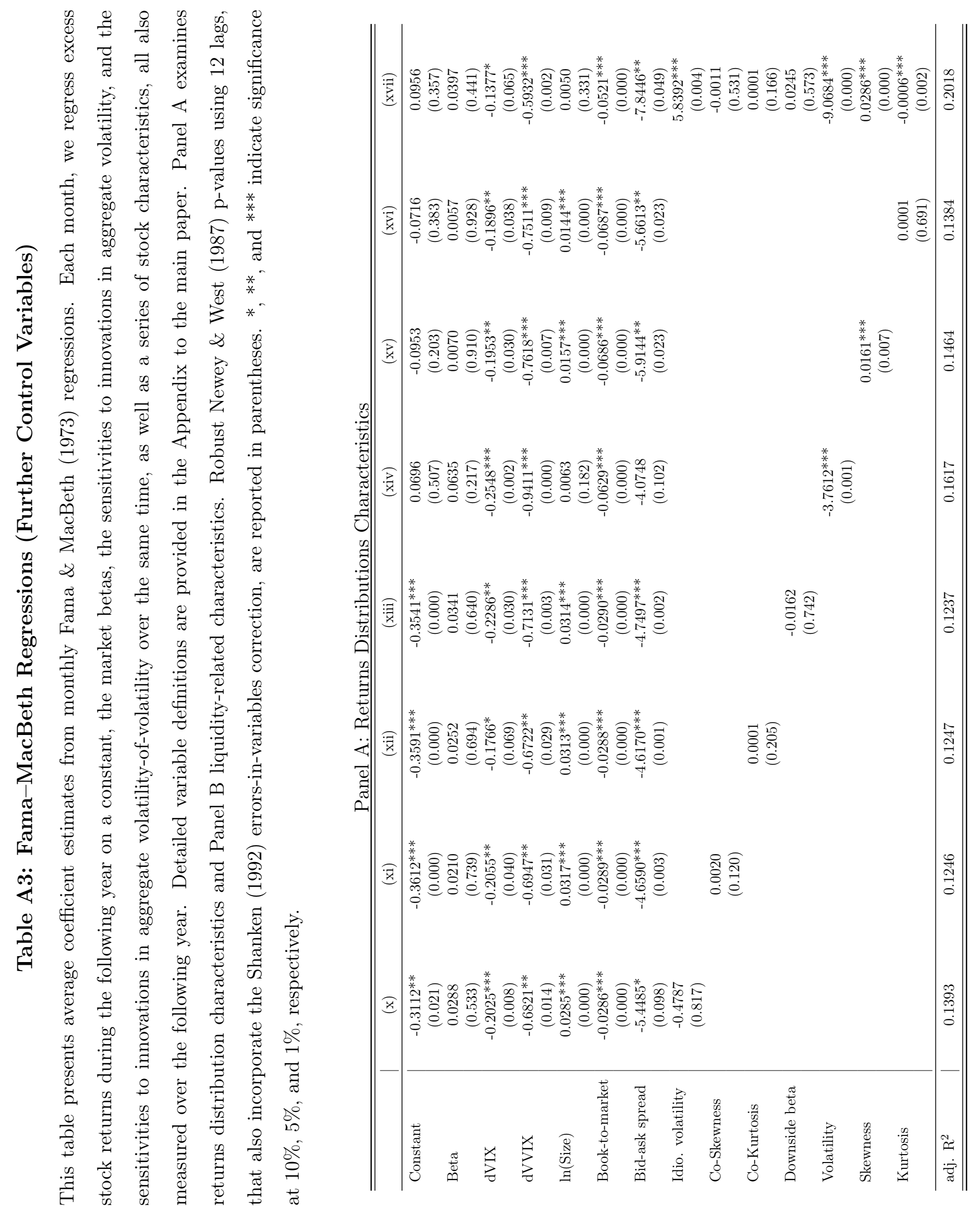




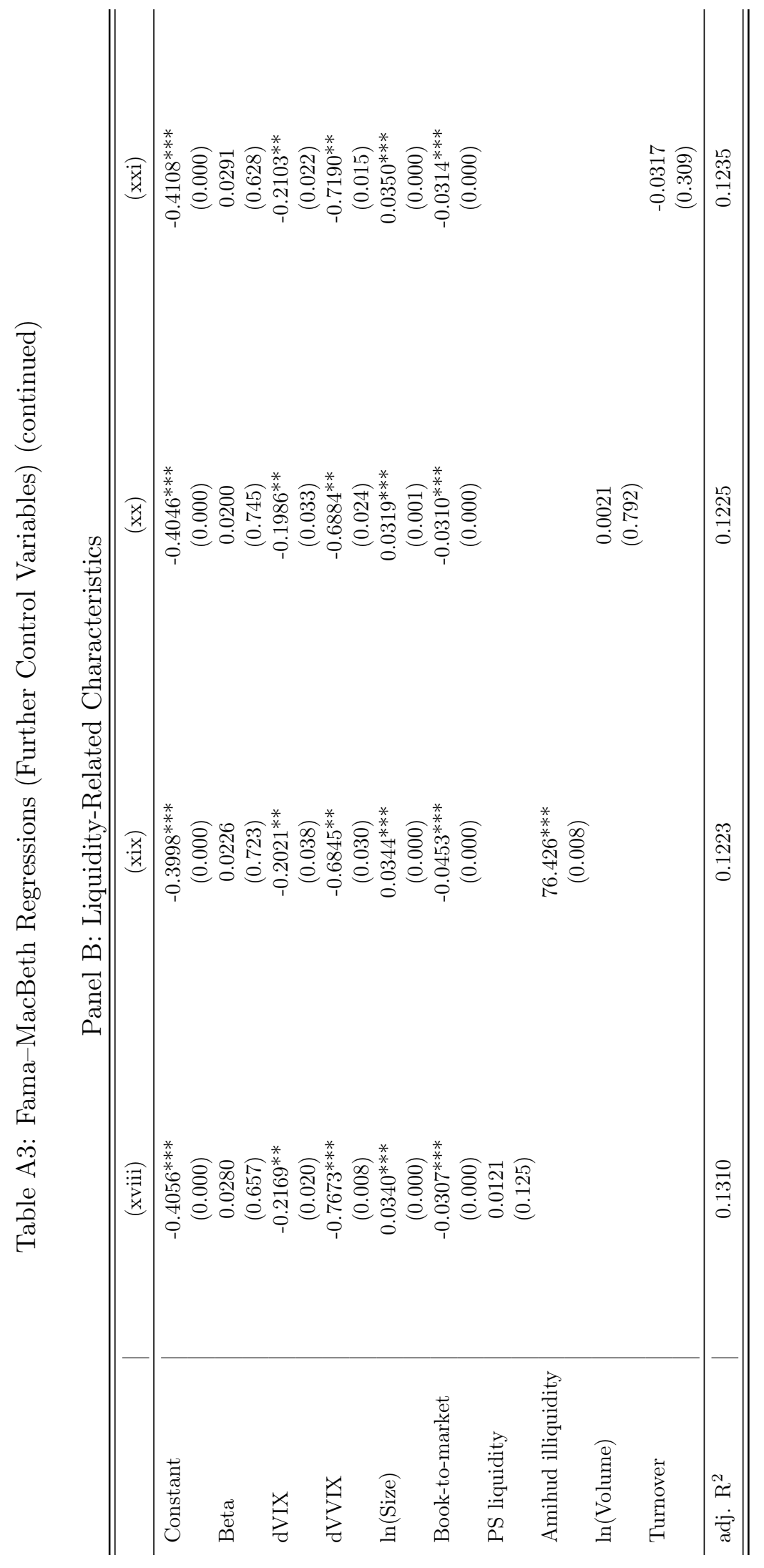




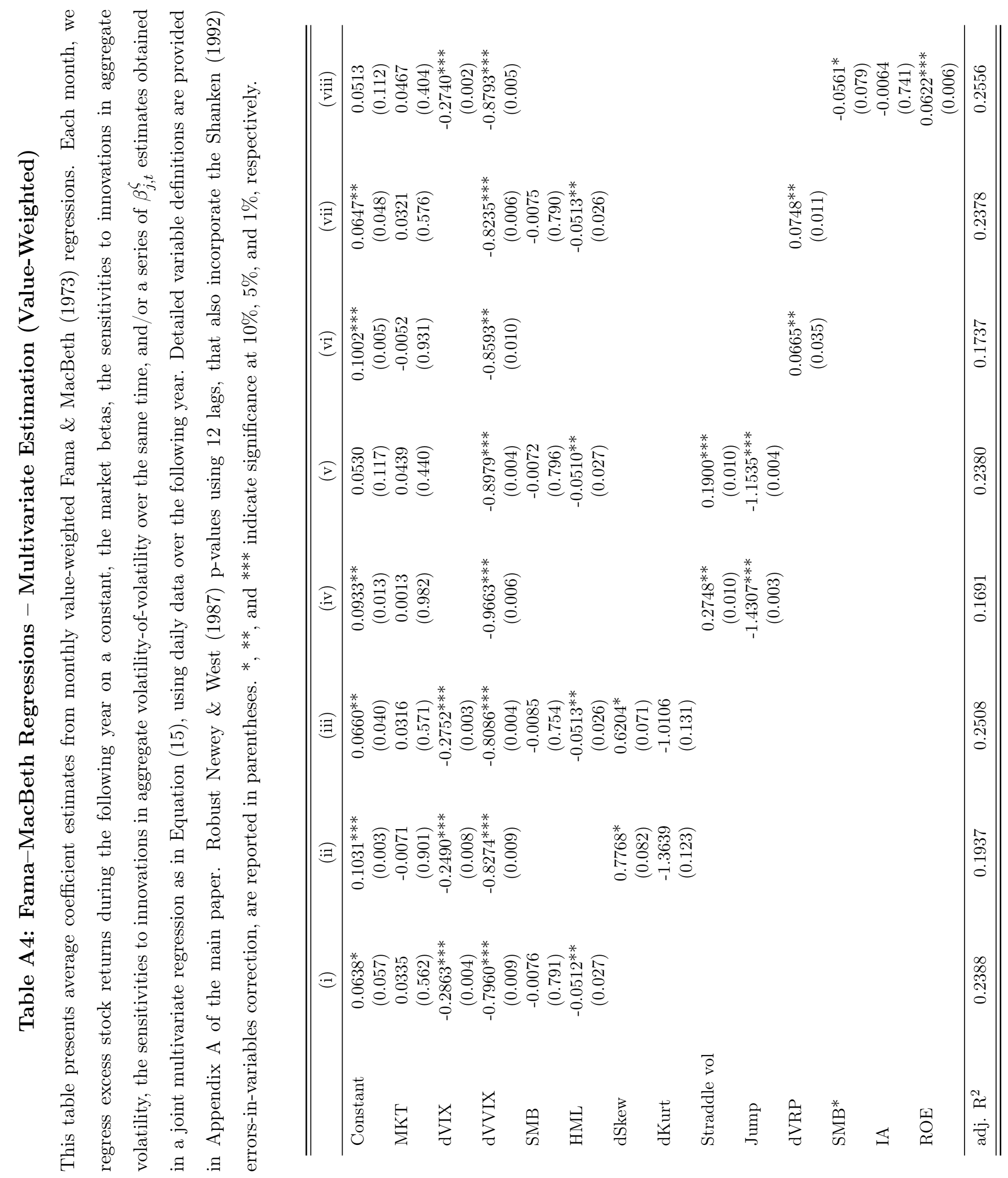




\section{Table A5: Realized Measure of Aggregate Volatility-of-Volatility}

At the beginning of each month, we form equally weighted quintile portfolios based on the stock's sensitivities to innovations in aggregate volatility-of-volatility $\left(\beta_{j, t}^{\mathrm{Q}}\right)$, measured as the realized volatility of the VIX, over the following year. The extended sample period spans January 2000 until September 2016. To obtain the sensitivities, we regress daily excess stock returns on dVoVIX, controlling for MKT and dVIX as in Equation (14). Stocks with the lowest $\beta_{j, t}^{\mathrm{Q}}$ are sorted into portfolio 1 , those with the highest $\beta_{j, t}^{\mathrm{Q}}$ into portfolio 5. The column labeled 5 minus 1 refers to the hedge portfolio buying the quintile of stocks with the highest $\beta_{j, t}^{\mathrm{Q}}$ and simultaneously selling the stocks in the quintile with the lowest $\beta_{j, t}^{\mathrm{Q}}$. Each month, we set up new 12-month portfolios. The row labeled Mean return is based on monthly simple returns. CAPM alpha, 4-factor alpha, and 5-factor alpha refer to the alphas of the CAPM, the Carhart (1997) 4-factor, and the 5-factor (including liquidity) models, respectively. HXZ alpha denotes the alpha relative to the Hou et al. (2015b) factor model. The segment Horizon 06-16 presents the results when restricting the sample period to the time frame between 2006 and 2016. Robust Newey \& West (1987) p-values using 12 lags are reported in parentheses. ${ }^{*}, * *$, and $* * *$ indicate significance at $10 \%, 5 \%$, and $1 \%$, respectively.

\begin{tabular}{l|ccccc|c}
\hline \hline Rank & 1 & 2 & 3 & 4 & 5 & 5 minus 1 \\
\hline Mean return & 0.0798 & $0.1004^{* * *}$ & $0.1019^{* * *}$ & $0.0961^{* *}$ & 0.0457 & -0.0341 \\
& $(0.106)$ & $(0.007)$ & $(0.006)$ & $(0.025)$ & $(0.462)$ & $(0.186)$ \\
\hline CAPM alpha & 0.0161 & $0.0547^{* * *}$ & $0.0578^{* * *}$ & $0.0453^{* *}$ & -0.0280 & $-0.0441^{*}$ \\
& $(0.224)$ & $(0.004)$ & $(0.005)$ & $(0.032)$ & $(0.259)$ & $(0.080)$ \\
4-factor alpha & -0.0008 & $0.0251^{* * *}$ & $0.0235^{* * *}$ & $0.0100^{*}$ & $-0.0647^{* * *}$ & $-0.0639^{* * *}$ \\
& $(0.956)$ & $(0.000)$ & $(0.000)$ & $(0.086)$ & $(0.000)$ & $(0.003)$ \\
5-factor alpha & -0.0052 & $0.0188^{* * *}$ & $0.0200^{* * *}$ & $0.0102^{* *}$ & $-0.0499^{* * *}$ & $-0.0447^{* * *}$ \\
& $(0.663)$ & $(0.000)$ & $(0.000)$ & $(0.047)$ & $(0.000)$ & $(0.006)$ \\
HXZ alpha & -0.0088 & 0.0095 & $0.0089^{*}$ & 0.0088 & $-0.0366^{* *}$ & -0.0278 \\
& $(0.330)$ & $(0.128)$ & $(0.072)$ & $(0.183)$ & $(0.039)$ & $(0.234)$ \\
\hline \hline Horizon 06-16 & \multicolumn{7}{c}{} & & & & \\
\hline Mean return & 0.0978 & $0.0978^{*}$ & $0.0964^{*}$ & 0.0926 & 0.0548 & -0.0430 \\
& $(0.111)$ & $(0.062)$ & $(0.071)$ & $(0.129)$ & $(0.489)$ & $(0.249)$ \\
\hline HXZ alpha & 0.0051 & $0.0204^{* * *}$ & $0.0149^{* *}$ & 0.0068 & $-0.0559^{* * *}$ & $-0.0610^{* * *}$ \\
& $(0.553)$ & $(0.000)$ & $(0.021)$ & $(0.396)$ & $(0.000)$ & $(0.004)$ \\
\hline \hline
\end{tabular}

